"POST-PRINT VERSION"

A Review on the Characteristics of Cyber-Physical Systems for the future Smart Factories

\author{
Alessia Napoleone ${ }^{\mathrm{a} *}$, Marco Macchi ${ }^{\mathrm{a}}$ and Alessandro Pozzetti ${ }^{\mathrm{a}}$ \\ ${ }^{a}$ Department of Management, Economics and Industrial Engineering, Politecnico di Milano, \\ Milano, Italy \\ *+393331306 533,+390223994763, alessia.napoleone@ polimi.it
}

To cite this article: Alessia Napoleone, Marco Macchi, Alessandro Pozzetti. A review on the characteristics of cyber-physical systems for the future smart factories. Journal of Manufacturing Systems, vol. 54, January 2020, 305-335, Elsevier B.V., ISSN: 02786125, DOI: 10.1016/j.jmsy.2020.01.007. 


\section{A Review on the Characteristics of Cyber-Physical Systems for the future Smart Factories}

The emergence of new technologies is providing new ways to compete in the current context of changeable and unpredictable market requirements. The focus of this paper is on Cyber-Physical Systems (CPSs), as one of the most promising transformative technological concept of such a context, thus considered by literature as the building blocks of future smart factories. However, CPSs are still in their conceptualization phase. To this end, much literature effort has been put on their technological characterization, while there is a lack of knowledge on operations management characterization to manage such new systems. To contribute in this latter direction, this paper reviews literature in order to distinguish between technological characteristics of CPSs and operations management characteristics to build future CPS-based smart factories. This paper remarks the need for research on operations management characteristics as these may be the ones actually leading operations managers to the concrete implementation of CPS-based factories in manufacturing.

Keywords: Cyber-Physical System, Smart Factory, Digitalization

\section{Introduction}

Nowadays, manufacturing firms are facing the challenge of keeping their competitiveness despite a scenario whose protagonists are the unpredictability of market requirements and technological evolution [1-4]. In this context, fervent research activity is addressing the development of CyberPhysical Systems (CPSs) in manufacturing: according to literature, CPSs can quickly adapt to unexpected changes [5,6], improving the competitiveness of firms [7-10].

More and more researchers agree that CPSs will become the building blocks of future factories [11-13]. Indeed, CPSs represent one of the most significant directions in the development of computer science and ICT in an industrial context. As such, CPSs are "systems of collaborating computational entities which are in intensive connection with the surrounding physical world and its 
on-going processes, providing and using, at the same time, data-accessing and data-processing services available on the internet" [14]. To this end, CPSs are able to: (i) collect data referred to themselves and their environment, (ii) process and evaluate these data, (iii) connect and communicate with other systems, and (iv) initiate actions [15]. According to Garetti, Fumagalli and Negri [16], CPSs are made of collaborating computational elements (such as micro computing units, or embedded systems, interacting through a communication system) deeply connected to, and controlling, physical entities. To them, in CPSs many types of equipment (i.e. sensors, actuators, devices, machines and robots) are creating a smart community with the capability to capture data and take actions on the physical world. This capability is potentially built through different production levels (i.e. from sensors to machines/ robots, up to the whole factory). All in all, CPSs transfer raw data to actionable operations, assisting users to comprehend process information, and adding resilience to the manufacturing system through an evidence-based decision making $[17,18]$. To remark the application in manufacturing, many authors referred to Cyber-Physical Production Systems (CPPSs) instead of CPSs (see for example $[19,20]$ ). Thus, in this paper, the two nomenclatures have been considered as synonyms.

Manifold definitions traceable within the scientific community are an evidence of the strong interest in CPSs as a relevant technology-related concept to build future smart factories. Coherently, as CPS-related theory is in its initial stage of development, much literature effort has been put on the technological characterization of such systems; moreover, the technologies required to develop CPSs are already available for manufacturing firms. Nevertheless, the concrete application of these CPSrelated technologies in order to enable the CPS-based smart factory is still far from turning into reality, as witnessed in currently published works. The introduction of CPSs leads to new requirements in the operations management of a factory. Operations managers should be made aware that there are some "technological" characteristics (in a broad sense, also involving specific competences, skills and functionalities offered by technology providers and production resources) that, by analogy with bricks to build constructions, should be the base to create a smart factory. Such 
smart factory differs from a traditional one because its inherent property is the capability to promptly evolve over time thanks to its "operations management" characteristics. To add a contribution in this direction, two research questions (RQs) are addressed in the paper:

- RQ1: What are the technological characteristics of CPSs in manufacturing emergent from existing literature?

- RQ2: What are the operations management characteristics to build CPSs-based smart factories?

To address the RQs, this paper reviews and sorts literature. Specifically, section 2 describes the adopted methodology. Section 3 digs into literature to identify and aggregate the characteristics of CPSs; section 4 answers to the two RQs by further aggregating and enriching characteristics, leading to their classification in characteristics of CPSs - i.e. technological (in a broad sense) ones and characteristics to build CPS-based smart factories - i.e. operations management ones. Finally, section 5 draws the conclusions and the future developments of this research.

\section{Adopted methodology}

In order to identify and understand the characteristics of CPSs, a structured literature review was performed. Specifically, taking into account the peculiarities of the operations management field compared to other fields such as medicine, the guidelines provided by Durach, Kembro and Wieland [21] were followed as detailed in the remainder. Moreover, the review articles written by specific authors in this field $[22,23]$ were taken as guidelines.

The review process has been synthesized in the following flow chart (Figure 1). 


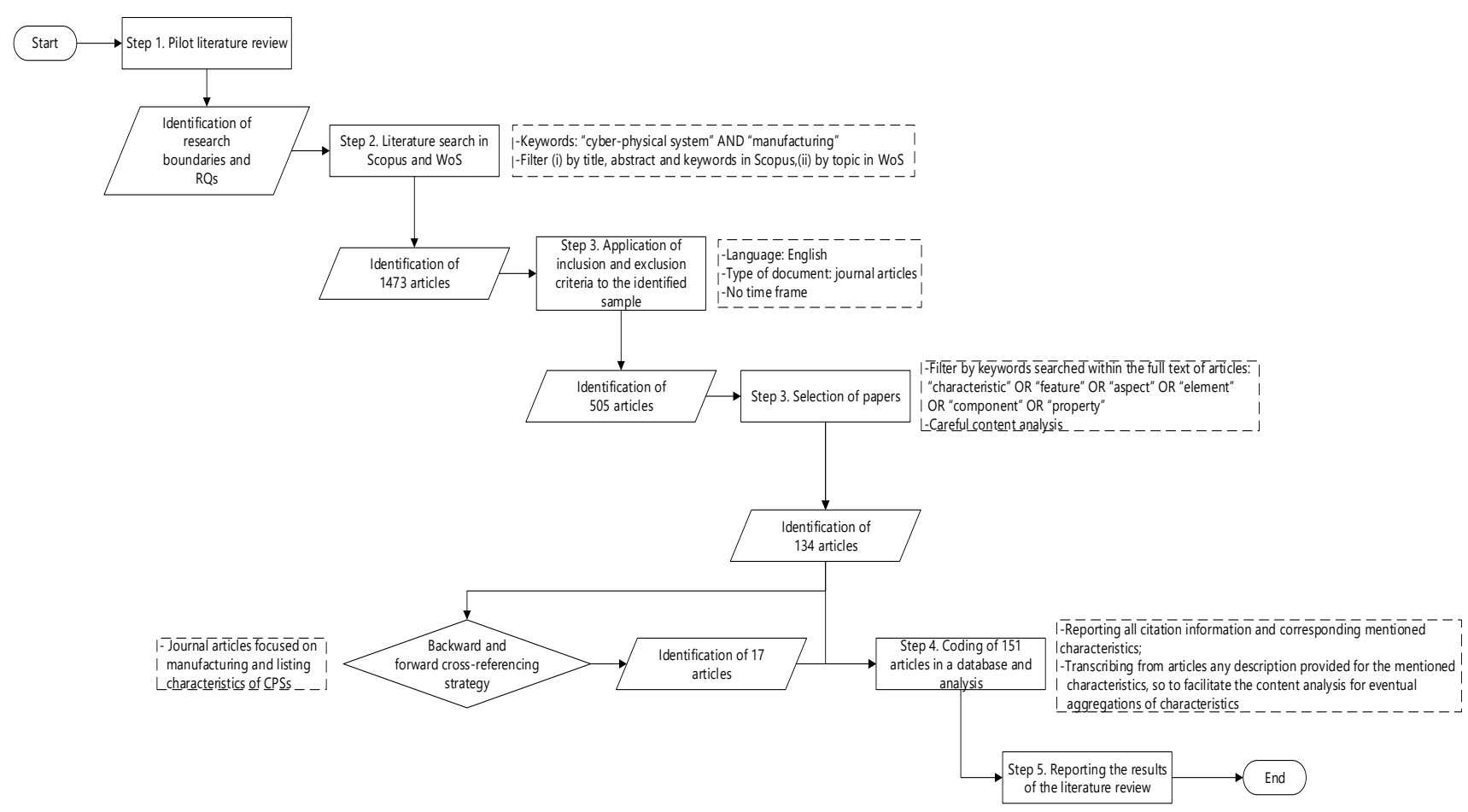

Figure 1 Adopted methodology

In a first step, the two relevant research questions were identified through a pilot literature review; the participation of the present authors in research and development projects in industrial settings had been influent to drive the pilot review. Consequently, the boundaries of the review were defined as argued in section 1 .

In a second step, the sample of potentially relevant literature was identified. In order to find relevant papers from the academic point of view, the search databases used for the investigation are Scopus and WoS. To ensure the coverage of the research questions, the keywords "cyber-physical system" and "manufacturing" were combined through an AND Boolean operator. To remain in the research boundaries, articles identified through the Scopus database were filtered by article title, abstract and keywords; those identified through the WoS database were filtered by topic. Overall, 1473 works were identified (1466 on Scopus, 286 on WoS and 279 on both the search engines).

In a third step, the pertinent literature was selected by applying appropriate inclusion and exclusion criteria to the identified sample, as detailed below.

- To ensure the high impact of the selected articles in terms of readership, only articles 
written in English language were reviewed.

- To ensure the quality of reached primary studies, only journal articles were considered.

- To ensure the reliability and validity of the findings, theoretical, empirical and review papers were considered.

- Finally, no time frame was set as literature on the application of CPSs in manufacturing is relatively recent.

By applying the aforementioned criteria, a set of 505 articles was identified (491 in Scopus, 127 in WoS and 113 on both the search engines). In order to further select literature, the so identified set of articles was analysed in different ways. Firstly, to identify the characteristics of CPSs, the keyword "characteristic" (or "feature", "aspect", "element", "component" and "property") was searched within the full text of the identified 505 articles, so to ensure the identification of any article relevant to the purpose of the present paper. Once the keywords had been detected, corresponding text was examined in order to verify if such words were used in association to CPSs and, if so, to select those articles listing specific sets of characteristics. Following this procedure, a total of 134 articles listing characteristics of CPSs was selected. Furthermore, through a backward and forward cross-referencing strategy, other 17 journal articles were added within the scope of the investigation as they were focused on manufacturing and listing characteristics of CPSs.

In a fourth step, the 151 relevant articles were carefully analysed and coded in a database, reporting all citation information and corresponding mentioned characteristics. Whenever articles provided descriptions for the mentioned characteristics, these were reported in the Excel database so to facilitate the content analysis for eventual aggregations of characteristics. The overall set of 151 relevant articles is authored by 427 researchers and, as shown in the following chart (Figure 2), some of the researchers authored more than one work (for example Xu X. contributed to 10 of the 151 articles). This aspect was taken into account during the analysis and consequently to draw the results of the review as explained below. 


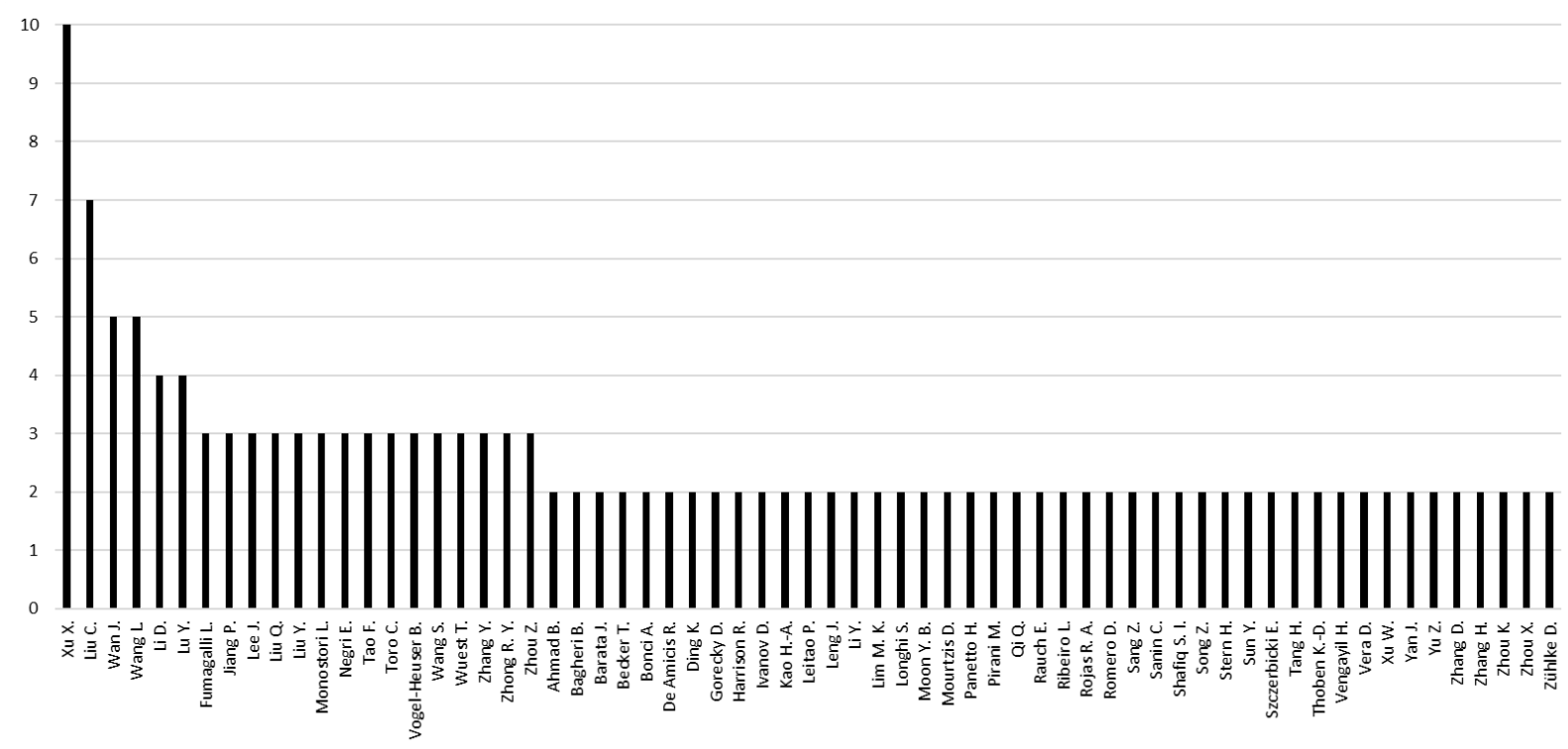

Figure 2 Researchers with multiple authorship within the sample

In a final step (as specified in the methodology suggested by Durach, Kembro and Wieland [21]), the results of the review were reported as detailed in the two results sections (i.e. sections 3 and 4).

The following flow chart (Figure 3) synthesizes the results of the literature review.

(Figure 3 here) 


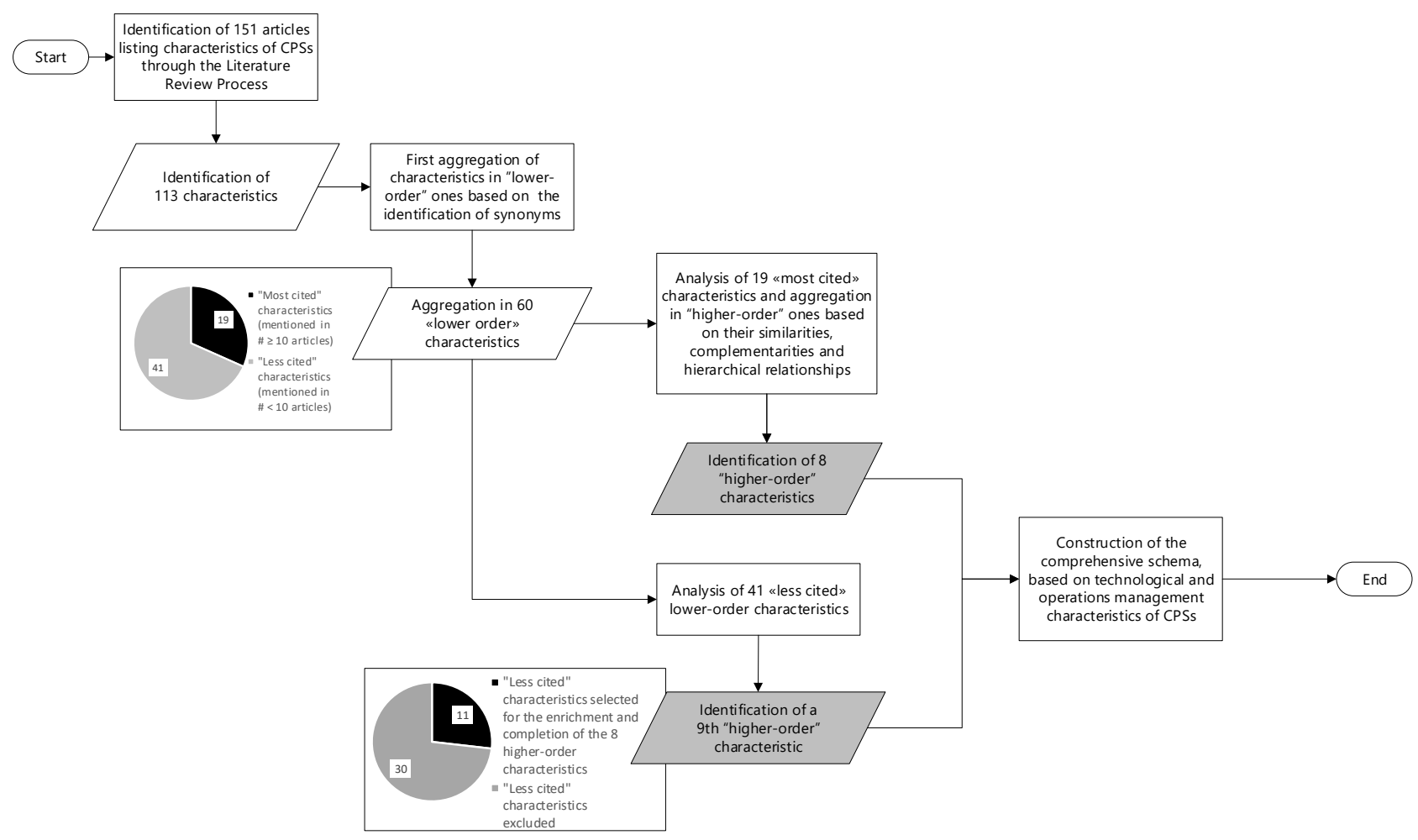

Figure 3 A summary of the results of the literature review

Based on the selected 151 articles, an extended list of 113 characteristics was identified. In this list, based on literature-based definitions, many of these characteristics were considered as synonyms and were grouped together as they can be intuitively overlapped (see for example connectivity and connectedness); therefore, the 113 characteristics were led back to a set of 60 "lower-order" characteristics. In the appendix, Tables A.1 and A.2 detail the results of this analysis: they specify articles mentioning specific characteristics (or their reported synonyms) and, in their last row, they provide the total number of articles mentioning such characteristics as indicator proxy for their current recognition in literature. Overall, 19 lower-order characteristics (i.e. those reported in the columns of appended Table A.1) were "most cited" ones as mentioned by at least 10 references.

As detailed in section 3, the literature-based definitions of the 19 most cited lower-order characteristics were analysed. Based on their definitions, these characteristics were further grouped together, based on their: (i) similarities, (ii) complementarities and (iii) hierarchical relationships. As a result, they were led back to a total of eight "higher-order" characteristics. 
As detailed in section 4, in order to enrich and complete the eight higher-order characteristics, the literature-based definitions of the 41 "less cited" lower-order characteristics (those reported in the appended Table A.2) were also analysed and, based on their semantic meaning, some of them - i.e. a total of 11 lower-order characteristics - were selected. This further analysis led to the addition of a ninth higher-order characteristic to the set of eight characteristics previously identified. The remaining 30 "less cited" lower-order characteristics were excluded by the present authors because either: (i) their semantic meanings do not provide a particular enrichment or completion to the most cited characteristics; or (ii) are outside the scope of this paper since they refer to business performances while the paper is focused on technological and operations management characteristics.

To avoid any bias due to the presence of researchers with multiple authorship, the two results sections (i.e. sections 3 and 4) - which actually describe the characteristics exploiting concepts developed in the available literature - were built using the observations of as many authors as possible. For this reason, other articles outside the sample of 151 articles and reached by searching on Scopus and WoS the combination of the keywords "cyber-physical system", "manufacturing” with any of the characteristics reported in Tables A.1 and A.2, contributed to build the results sections (i.e. sections 3 and 4).

Lastly, the nine higher-order characteristics were classified in technological (thus, associable to CPSs) and operations management ones (thus, associable to the entire CPS-based smart factory). The overall representation of groups of characteristics and relationships were synthesized in a comprehensive schema.

\section{Characteristics of CPSs according to literature}

This section focuses on the 19 most cited lower-order characteristics, providing their literature-based descriptions and explaining the reasoning behind their aggregation in eight higher-order characteristics, identified by the abbreviations $\mathrm{C} 1, \mathrm{C} 2, \mathrm{C} 3, \mathrm{C} 4, \mathrm{C} 5, \mathrm{C} 6, \mathrm{C} 7$ and $\mathrm{C} 8$. A list of abbreviations is provided in the appendix. 
The remainder of this section - organized in correspondent sub-sections - illustrates how the analysis led to such aggregation. As for narration, the following logic is adopted for each of the eight higherorder characteristics:

- Firstly, a brief analysis of literature leading to the identification and justification of similarities (if any) between characteristics is presented. When present, such similar characteristics are stylistically described within the same bullet point.

- Secondly, a brief analysis of literature leading to the identification and justification of relationships (if any) between characteristics is provided (both their complementarities and hierarchical relationships were considered). When present, relationships are stylistically described within dedicated final bullet points.

\subsection{Complexity/heterogeneity encapsulation (C1)}

- Complexity/heterogeneity encapsulation. In manufacturing, the complexity of CPSs is due to the different nature of their elements. CPSs are often equipped with embedded systems (software and hardware) able to generate, communicate, and evaluate huge amounts of data about the ongoing production processes [24]. Indeed, CPSs are made of elements having heterogeneous nature $[5,25,26]$. According to Yuan, Anumba and Parfitt [27], CPSs are heterogeneous because they integrate several different systems together with standard communication and information exchange. They integrate various devices, including sensors, mobile devices, workstations and servers. Many authors remarked that CPSs' complexity/heterogeneity should be properly encapsulated and managed $[15,28,29]$. Even when referring to the "management" or "handling" of complexity/heterogeneity $[29,30]$, the characteristic has typically been interpreted as a design requirement [8,31]. Indeed, the complexity has to be "encapsulated" during the engineering process (see [32,33]). Moreover, dynamic processes of heterogeneous systems included in CPSs should be properly designed, characterized and controlled [10,25,34]. All in all, handling the complexity and the heterogeneity is an issue related to the integration problem: it should be solved through proper solutions of encapsulation of systems and devices [7,31,33,35-37]; indeed, 
encapsulation can be considered a general design principle inherent to CPSs.

\subsection{Interoperability, connectivity, communication, networking capability (C2)}

- Interoperability. Interoperability is the capability of system components to connect, communicate, and operate with each other $[9,38]$. In other words, interoperability allows CPSs to exchange mutually intelligible information [39]. A critical factor for interoperability is standardization because components have to understand with each other [5,40,41]. Ghobakhloo [38] emphasized that interoperability differs from data standardization, as it is concerned with the meaning of the contents of the data and how different components of a system can communicate and understand the meaning of the data, and make a decision based on it. On the other hand, interoperability is enabled by standardization [42]: according to Leitao et al. [5], within heterogeneous CPS systems, the interoperability and the understanding of shared knowledge is an important aspect; to this end, standards addressing interoperability, information exchange and interfaces to legacy systems must be considered. Having similar concerns, the interoperability of CPSs allows reducing some relevant costs of manufacturing systems by avoiding the effort of building customized integration of their components [43].

- Similarity of communication and connectivity. The communication or, equivalently, connectivity characteristic of CPSs ensures real-time data acquisition from the physical world and information feedback from the cyber space [44-46]. Indeed, CPSs consist of entities that are connected, based on the context, within and across all levels of production activities, from machine operation, process control, up to entire production and logistics networks $[32,47,48]$. According to Wang, Torngiren and Onori [49], communication between CPSs may rely on the Internet. To them, when involving the Internet, CPSs are Internet of Things (IoT) Systems (systems in which components provide data over the Internet). Thus, the IoT is an important enabler of CPSs [50-52]. For example, Tedeschi et al. [52] remarked that Internet of Things (IoT) is an important and innovative technology used to defining internet protocols to allow 
communication between machines, devices, objects and sensors. According to Isaksson, Harjunkoski and Sand [50], IoT means that any device can be connected to the internet allowing two-way communications across or between production systems: this makes new data available also across operations and supports more horizontal applications with decentralized decision making. As stated by Laird [51], relying on the infrastructure provided by the IoT, CPSs can share and analyse data and, based on what they learn, they can send out control commands to physical resources: by doing so they monitor and control the physical processes.

- Networking capability. The networking capability can be described using the words of many authors [53-55]: CPSs should be composed of interconnected clusters of processing elements and physical elements in large-scale wired and wireless networks through a variety of sensors and actuators, aiming at constructing intelligence across different fields. Connecting these fields usually relies on the Internet; dynamic participation in the network is herein possible.

- Hierarchical relationships between the characteristics in C2. Building CPSs in manufacturing requires achieving interoperability, as base requirement for information exchanges amongst CPSs. In other words, interoperability allows developing the communication and connectivity of CPSs, indeed such systems connect with each other and with humans communicating via standard interfaces [56]. To some authors, connectivity allows manufacturing objects to set-up and use connections to other objects of a system $[57,58]$. Overall, the networking capability is enabled by the characteristics of interoperability, communication and connectivity $[39,59,60]$. To this end, many authors also referred to the "network connectivity" characteristic [25,61-64], which ensures that the sensing data can be successfully delivered from each sensor to specific network nodes.

\subsection{Service orientation $(\mathrm{C} 3)$}

- Service orientation. Through interconnection and communication, complex manufacturing tasks can be accomplished collaboratively by several manufacturing "services" [38]. Indeed, Yuan, Anumba and Parfitt [27] referred to the ability of CPSs to provide timely service in order to deal 
with real-time constraints. In CPSs, cyber aspects also include digital services encapsulated in service-oriented architectures [65]. The design of such architectures promises rapid integration of data and business processes $[66,67]$. In a service-oriented structure, the functionality implemented by each entity - in the CPSs' environment - is easily accessible to the others $[42,68]$. Moreover, following service-oriented constraints when developing the control logic of a system is a way to handle the complexity of integration [35].

From a different perspective, another footprint of service orientation is the growth expected for service/app marketplaces applied to smart manufacturing [15]. App/service marketplaces had gained significant attention in recent years as they offer flexibility, while the advances in cloud computing and cloud manufacturing support this claim [69]. Therefore, flexible app/service marketplaces that offer a set of core apps and allow users, or independent third parties, to develop customized apps focusing on certain issues in smart manufacturing realm, are desired by industries and researchers [4].

\subsection{Modularity, autonomy, self-capabilities, decentralization (C4)}

- Modularity. Modularity is the capability of a CPS to be modularized, flexibly changed, and reconfigured in response to rapidly changing customer needs and product changes $[1,9,70]$. Thus, modularity allows system independence, making it capable to adapt more flexibility [29]. Therefore, modularity is another important enabler of CPSs; indeed, according to Lins et al. [71], to enable their adaptability, CPSs are supposed to be developed in a plug-and-work manner, e.g., by aggregating predefined system modules and machine components (such as robots, conveyors and CNC machines).

- Similarity of Autonomy and Self-capabilities. Fettermann et al. [72] associated autonomy to the capacity of CPSs to independently learn and adapt to the environment. According to Ribeiro and Bjorkman [73], CPS are complex and evolving entities with a high degree of autonomy. Such autonomy should be appropriately designed so to ensure the adaptive response to disturbances of 
components, enabling them to recover from localized changes. Rosenberg et al. [9] and Pirvu, Zamifirescu and Gorecky [74] described the autonomy of CPSs as their capability to close the control loop over their life-cycle, also assimilating the human factor, thus regardless of their automation degree.

Autonomy brings to the self-capabilities of CPSs. Self-capabilities can in fact be seen as exemplifications of autonomy [10,53]. Instances of self-capabilities are self-adaptivity [75], selfreconfiguration, self-organization [24], self-awareness [18], self-learning [76], self-diagnosis [5], self-healing [77], self-optimization [11], self-protection, and self-explaining [29].

- Decentralization. Decentralization means having CPSs working independently and making decisions autonomously in a way they remain aligned with the path toward the single ultimate organizational goal [38]. Distribution, as synonym of decentralization, has often been referred to the control/decision-making system of CPSs $[47,78,79]$. The components of a distributed system are located on networked computers, communicating and coordinating their actions by exchanging information to meet common goals [34].

- Hierarchical relationships between the characteristics in C4. Modularity enables autonomy of CPSs, i.e. the capability to perceive and interact autonomously with their physical environment over their lifecycle [80]. An overall effect of the autonomy/self-capabilities of CPSs, is the change from centrally-structured to decentrally-structured control [36]: thus, decentralization is the ability of CPSs within smart factories to make decisions on their own $[1,9,81]$.

\subsection{Integration}

- Integration. Integration is a necessary and challenging issue for CPSs: CPSs are, indeed, integration of computation and physical processes $[49,82,83]$. Penas et al. [12] remarked that CPSs integration is a design concern (concerning physical systems, software and platform engineering) allowing future faster design of existing process networks between production resources. 
- Hierarchical relationships of Integration with C1, C2, C3 and C4. Integration can be seen, and is interpreted as such in this paper, as a more comprehensive characteristic: it can be associated to multiple higher-order characteristics, C1, C2, C3 and C4, as detailed below.

Firstly, integration is enabled by the complexity/heterogeneity encapsulation (C1) and the networking capability $(\mathrm{C} 2)$. Indeed, the complexity/heterogeneity encapsulation $(\mathrm{C} 1)$ is a general design principle inherent to CPSs that looks for solutions of integration of several different systems, also thanks to standard communication and information exchange $(\mathrm{C} 2)[5,8]$. Another characteristic enabling the integration of complex/heterogeneous systems is the serviceorientation (C3): following service-oriented constraints when developing the control logic of a system is a way to handle its integration [35]. Furthermore, the growth of attention over App/service marketplaces, with the advances in cloud computing, offers flexibility in integrating even customized functionality [69]. The characteristic of decentralization (C4) also enables the integration characteristic: in fact, the decentralization of CPSs has the operational effect of their capability to work independently and make autonomous decisions while being aligned toward a systemic goal [38].

\subsection{Virtualization, real-time capability (C5)}

- $\quad$ Virtualization. Many authors $[1,9,70,81]$ described virtualization as the ability to link sensor data to virtual factory models and simulation models; in other words, virtualization consists in creating a virtual copy of the real physical world and remaining connected to it over time. It allows CPSs both to remotely analyse and track physical processes [27], to simulate behaviours [84] and, in some cases, to allow a communication feedback from the digital world to the field [85]. Ghobakhloo [38] observed that virtualization enables the replication of a "digital twin" of the entire value chain (smart warehouse, smart factory, all related equipment and machinery, and even smart products). Sanderson, Chaplin and Ratchev [86] described the "digital twin" as a digital replica of the real system; such digital twin, supported by context-awareness, allows all 
elements in the factory to be fully traceable [86] for all their lifecycles granting the so-called digital continuity of the data about the systems, accompanying them from the design to operational and dismissal phases [87]. More comprehensively, Cimino, Negri e Fumagalli [88] defined digital twins as simulation environments which are hosted by, or connected to, the cyber part of CPSs. To them, such environments not only should allow CPSs monitoring physical resources, but also acting on such resources based on simulations results. Indeed, as remarked in some works $[23,89]$, simulation comprises an indispensable set of IT tools and methods for the successful implementation of digital manufacturing. It allows quick and cost-effective experimentation and validation of product, process, and system design and configuration.

- Real-time capability. Real-time capability is the ability of CPSs to acquire and analyse real-time data on equipment, quality and raw materials and provide the derived insights immediately $[1,9,90]$. It is a key characteristic as it allows CPSs to detect any change in the physical processes and react in real-time to ensure the functional and safety requirements of the system [91]. Thus, real-time capability might also imply physical actions to prevent failures [8].

- Complementarity relationships between the characteristics in C5. Virtualization and realtime capability are complementary characteristics. Indeed, the "digital twin" is a digital replica of the real system, it should allow the real-time visualization of and feedback on the current status of manufacturing components, so to instantaneously provide the derived insights $[1,86,92]$.

\subsection{Computational capability (C6)}

- Computational capability. Many authors (see, for example [38] and [9]) referred to the computational capability of CPSs. The provided definitions for such characteristic are all referred to data management and analytics carried out with methods/techniques from different domains (such as computer science and statistics). Therefore, the cyber parts of CPSs should be able to perform a significant amount of computation and control work previously performed by human, and today also strengthened by the possibility to share data and interact with each other [34,93]. 
Moreover, CPSs should be able to perform computing at any location, hence the concept of ubiquitous computing [94]. An enabler of such computational capability of CPSs is cloud computing $[95,96]$. In fact, cloud technologies provide an environment to connect and share distributed manufacturing resources including knowledge, computing and software tools, as well as physical resources via the Internet networking infrastructure [97].

\subsection{Intelligence/smartness}

- Intelligence/smartness. CPSs are supposed to have intelligence, alias smartness, as they are capable of being identified, sensing events, interacting with others, and making decisions by themselves [98]. Monostori [99] referred to the intelligent capabilities of CPSSs regarding data management, analytics and computation. CPSs bring computation and communication capabilities to physical components to create intelligence [100]. Such intelligence is distributed among entities [56,101]. More specifically, a CPS can use sensors and actuators to collect information about the physical operations in real-time and conduct intelligent control over physical systems to adapt to changing conditions and environment [48].

- Hierarchical relationships of intelligence/smartness with C5 and C6. Intelligence/smartness can be seen, and is interpreted as such in this paper, as more comprehensive characteristic because it can be associated to two higher-order characteristics, the virtualization and real time capability (C5) and the computational capability (C6). Indeed, CPSs exploit digitalization and real-time capability to collect and monitor information about the physical process in real-time [48], thus they bring the computation capabilities to process information and create intelligence $[99,100]$.

\subsection{Cooperation, collaboration $(\mathrm{C} 7)$}

- Similarity of cooperation and collaboration. In this work, cooperation and collaboration are considered equivalent characteristics, even if collaboration is generally a stronger concept entailing resource sharing and joint goals [102]. There is in fact a kind of continuum emerging in the current discussion, from cooperation to collaboration of CPSs. CPSs cooperate within the 
shop floor for carrying out tasks: they can control themselves for adapting to changes as well as cooperate with other CPSs to accomplish specific activities [103]. According to EtxeberriaAgiriano [8], cooperation is the capability of a distributed system with autonomous subsystems to dynamically decide which components will carry out a certain task in order to optimize performances such as the response time. Indeed, a good combination of autonomy and cooperation of CPSs confers smart factories specific characteristics such as self-organization and self-maintenance [103,104]. It is also worth remarking that many authors specified the inclusion of humans in such process of cooperation/collaboration between entities of the factory $[48,49,105]$. For example, Wang, Torngren and Onori [49] referred to the symbiotic human-robot collaboration, which combines the flexibility of humans and the accuracy of machines; they referred to the possibility for humans to instruct robots by speech, signs and gestures and the possibility for robots to assist humans in the implementation of tasks. Eventually, collaboration relies on the ability to share manufacturing information between different stakeholders at different locations [49]. Overall, in case of collaboration, involved parties share information, resources and responsibilities to jointly plan, implement and assess the set of activities required to achieve a common goal [102].

\subsection{Dynamic reconfigurability, adaptability (C8)}

- Similarity of dynamic reconfigurability and adaptability. Generally speaking, dynamic reconfigurability refers to the characteristic that enables quick responsiveness to market changes and disturbances [7]. In this perspective, CPSs allow achieving reconfigurable manufacturing $[5,12,106]$. Specifically, CPSs can evolve over time through dynamic reconfiguration of their structures, they can also reorganize their functionalities, change behaviour and modify their boundaries $[12,107]$.

Similarly, adaptability is the ability of CPSs to adapt to quickly changing situations and new requirements (such as new products or product variants) through dynamic reorganization/reconfiguration [27,108]. To this end, some authors remarked that adaptability 
relies on self-organization, learning and evolving capabilities of CPSs [74,104]. Adaptability is especially needed in case of dynamic and turbulent environments [35,109]. Rosenberg et al. [9] referred to the flexible adaptation of smart factories to changing requirements by replacing or expanding individual modules. Also to Panetto et al. [104], systems need to be modular to support modification and (self-)adaptation. To this end, Ribeiro and Bjorkman [73] remarked that the most important design feature to attain adaptability is to endow components at each level with enough autonomy to enact an adaptive response to disturbances, enabling them to deal with localized changes without having to rely on components at a higher level.

\subsection{Concluding remarks}

The following figure (Figure 4) synthesizes the aggregation of characteristics in the eight higherorder ones.

(Figure 4 here)
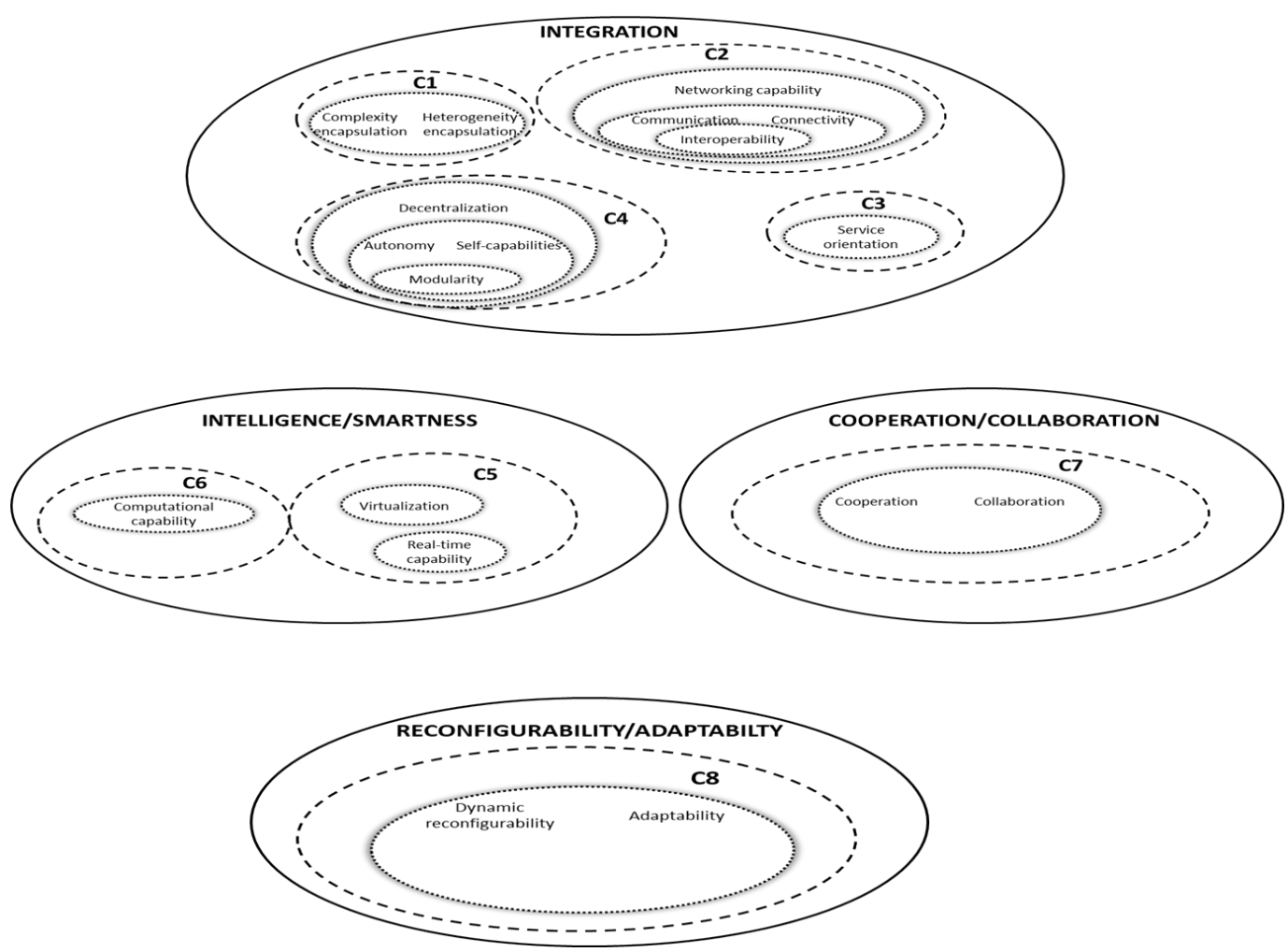

Figure 4 Aggregation of the most cited lower-order characteristics in eight higher-order characteristics

Similarities, complementarities or hierarchical relationships, used to aggregate lower-order in higher- 
order characteristics, are graphically represented as herein illustrated:

- in case of similarities (e.g. communication and connectivity in Figure 4), lower-order characteristics are represented in the same circles;

- in case of complementarities (e.g. virtualization and real-time capability in Figure 4), lowerorder characteristics are represented in juxtaposed circles;

- in case of hierarchical relationships (e.g. decentralization enabled by autonomy/ selfcapabilities in Figure 4), lower-order characteristics are represented in hierarchically contained circles (i.e., in the hierarchical relationship, contained circles are enablers of containing circles).

The lower-order characteristics shown in Figure 4, as most cited ones, were considered in this paper as "basic" characteristics. Indeed, these are the basis for the results of this paper.

\section{Characteristics to build CPS-based smart factories}

This section, enriches the characteristics shown in Figure 4 by adding therein selected less cited lower-order characteristics. As less cited ones, these 11 characteristics were considered in this paper as the ones whether "enriching" or "completing" the "basic" characteristics (i.e. the most cited ones). Finally, in order to address the RQ1 and RQ2, this section further aggregates the characteristics in technological and operations management ones. As anticipated in Section 1, the "technological" characteristics (in a broad sense, also involving specific competences, skills and functionalities offered by technology providers and production resources) should be the base (like bricks to build constructions) to create a smart factory, different from a traditional factory because capable to promptly evolve over time thanks to its "operations management" characteristics.

\subsection{Enrichment and completion of characteristics}


Definitions of the less cited characteristics (i.e. those reported in the appended Table A.2) were analysed and some of them were appropriately selected based on the knowledge of the present authors, as members of the scientific community and participants in industrial projects. According to their semantic meaning, the selected characteristics were associated to the "basic" characteristics shown in Figure 4. Some of them are described in the remainder as "enriching" the "basic" characteristics, as they can be interpreted as instances of those discussed in section 3 . Some others are described as "completing" the "basic" characteristics as they provide additional insights to the characteristics discussed in section 3. The completing characteristics are also represented in the following figure (Figure 5). As shown in Figure 5, this phase of investigation led to the addition of a new higher-order characteristic (C9) to the eight characteristics identified in section 3. 


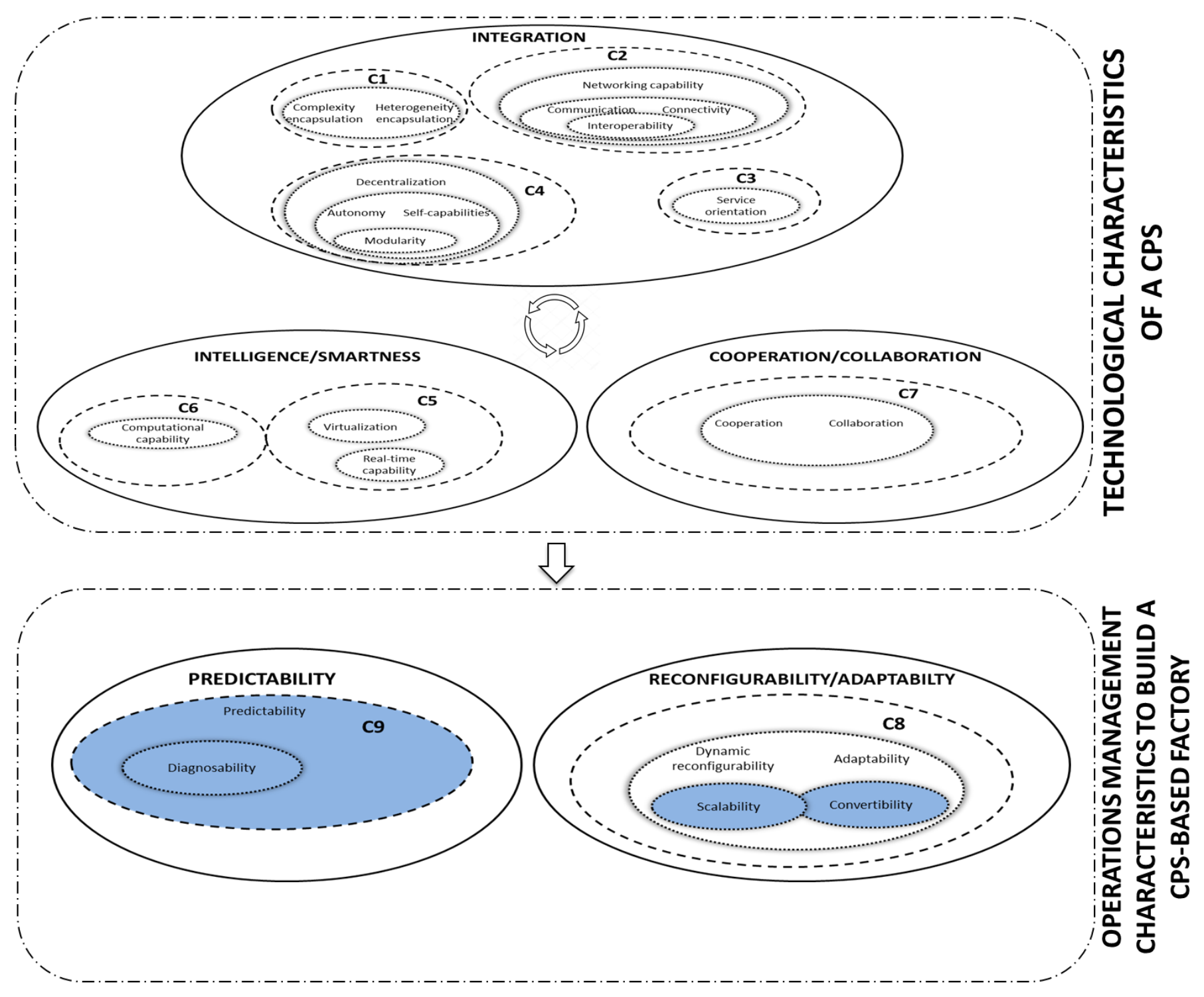

Figure 5 A comprehensive schema of characteristics of CPSs

\subsubsection{Enrichment of characteristics}

$\mathrm{C} 2$ is a characteristic given by the combination of a set of lower-order characteristics, whose overall effect is the networking capability (as discussed in section 3.2). According to literature, different kinds of interaction should be possible in CPSs: human-to-human, machine-to-machine and human to machine/robot/system [36,45,110]. As remarked by Emmanouilidis et al. [111], human integration in industrial environments is receiving increasing attention, with terms such as "Operator 4.0" used to denote the vision of human empowerment with Industry 4.0 technologies. For this reason, the human-machine interaction (which is a lower-order characteristic reported in Table A.2) is considered as a relevant example to be included in $\mathrm{C} 2$. Indeed, human presence is essential in CPSs. 
C5 is a characteristic given by virtualization and real-time capability as complementary characteristics. It is worth stressing that the real-time capability also includes the real-time visibility (which is a lower-order characteristic reported in Table A.2). Indeed, in a CPS, the current status of manufacturing components can be determined and visualized in real time [92]. For example, Chen and Tsai [94] referred to the application of RFIDs and auto IDs to manufacturing to develop core characteristics such as real-time objects tracking and increased asset visibility.

C6 is a characteristic that, in section 3.7, is described as computational capability. The authors considered appropriate to consider four other characteristics whose combination allows the enrichment of the computational capability. Indeed, the following characteristics (which are lowerorder characteristic reported in Table A.2) can be seen as complementary requirements for the intelligent behaviour of CPSs. These are: (i) the context awareness; (ii) the sensing (or perception) capability; (iii) the cognitive (or learning) capability and (iv) the actuation capability. Firstly, a context-aware CPS should assist people and machines in the execution of their tasks through the exploitation of sensors and actuators to trigger actions based on the environmental context [36]. Thus, systems should be self-aware of current state of the production process [112]. Secondly, in order to be able to perceive the context, the sensing capability, which relies on the presence of sensors, is required; according to $\mathrm{Wu}$, Terpenny, and Schaefer [113], multiple types of sensors should be adopted in intelligent CPS applications; these cross-domain sensing data are exchanged over heterogeneous network. Thirdly, sensed data should be exchanged and processed, remarking the relevance of the cognitive capability supporting to this end. The cognitive capability is considered as the ability of CPSs of knowing, thinking, and information processing [114], typically in relationship to the assistance of humans in the decision-making loop [17,18]. Finally, the actuation capability adds the implementation of actions in response to manufacturing problems within the physical environment; to give an example, Chen et al. [75] referred to cognitive robots, which can perceive information uncertainty, change scheduling management and adjust manufacturing behaviour to independently cope with a complex manufacturing problem; another example is a robotic CPS in order to enable 
safe human-robot collaboration without any fencing [15] through characteristics of dynamic task planning, active collision avoidance, and adaptive control in presence of humans.

C7 is a characteristic that, in section 3.7, was exhaustively synthesized as cooperation/collaboration. However, the authors considered appropriate to further stress the relevance of human presence, by including in C7 a specific example of cooperation/collaboration: the one between humans and machines (which is a lower-order characteristic reported in Table A.2). Emblematically, some authors referred to the "symbiosis" between humans and machines/robots to remark that such collaboration is designed not to replace but to augment the skills and abilities of humans, so to improve productivity and resources effectiveness [14,32,49,115].

\subsubsection{Completion of characteristics}

C8 is a characteristic synthesized as dynamic reconfigurability/adaptability. The authors considered scalability and convertibility (which are lower-order characteristic reported in Table A.2) as characteristics enabling the dynamic reconfigurability/adaptability (see Figure 5). Scalability allows changing the production capacity of a system quickly and with a low effort. It refers to the ability of complex CPSs to change during their life cycle, due to either a growing or shrinking number of "nodes" (nodes could be either participating or managed physical systems, sub-systems or components of the CPSs) [29]. According to Garcia-Valls et al. [116] scalability means that CPSs should contain the needed logic to deal with aspects such as moving nodes and joining/removing them. Relying on the logical and physical modularity of system components and on the standardization of the interfaces between such modules, CPSs should be scalable and composable [67,73]. Convertibility can be described as the capability of CPSs to extend the overall system functionality by relatively easily adding new functions, supported by modular manufacturing execution systems capable to inform on the current state and support better decisions [35].

Finally, a new characteristic - C9 - was added to the set of eight ones identified in section 3 (see Figure 5). This new characteristic results in the predictability, which, in turn, is enabled by the 
diagnosability (both predictability and diagnosability are lower-order characteristics reported in Table A.2). C9 is an essential operations management characteristic as it improves the capability of the CPS-based smart factory to react quickly to changes. Indeed, according to literature, predictability strengthens (i) the adaptivity of production and logistics [117] and (ii) the implementation of predictive maintenance [70]. For example, according to Lee, Bagheri and Kao [17], CPSs' capability to predict the behaviour of machines relies on degradation monitoring and remaining useful life prediction of machine components as well as predictive health monitoring of machines.

Predictability is the ability to predict CPSs' behaviour, supporting the detection of unexpected events and the root cause analysis in case of a failure [29]. As shown in Figure 5, predictability is enabled by the diagnosability of CPS-based smart factories: such factories should autonomously detect and diagnose the root cause of product defects or otherwise actively support users in their identification; moreover, they should operate in a traceable way [67,73]. Sun et al. [118] stressed the need to ensure the timeliness of the characteristic of predictability. Such timeliness can be achieved recurring to the diagnosability. Indeed, in smart manufacturing diagnosis and prediction of equipment faults will become routine and, in some cases, autonomous repair may take place [119]. For instance, intelligent machines may trigger maintenance processes autonomously and may be capable of predicting failures [120].

\subsection{Characteristics of CPSs and characteristics of CPSs-based smart factories}

The aforementioned schema (Figure 5) is a construct based on literature findings; it answers to the RQ1 and RQ2 by aggregating the aforementioned nine higher-order characteristics in two macrogroups: the technological (in a broad sense) ones, describing the CPSs, and the operations management ones, to build the CPS-based factory.

This construct relies on a distinction between technological and operations management characteristics: to the aim of this paper, technological characteristics are intended as structural enablers of operations management characteristics; the latter, unlike technological ones, need to be 
dynamically exploitable to deal with operational aspects, leading to the operational practices implemented in a CPS-based smart factory.

Thus, in Figure 5, a first macro-group includes the technological characteristics that describe CPSs (intended as technological systems included within the factory). It contains three groups of higher-order characteristics that were synthesized in section 3 as: (i) "Integration", (ii) "Intelligence/smartness" and (iii) "Cooperation/collaboration". The second macro-group drawn in Figure 5 includes the operations management characteristics to build CPS-based smart factories (intended as comprehensive systems made of CPSs with the purpose to develop new manufacturing applications leading to new operations management practices). This group includes the remaining higher-order characteristics: "Reconfigurability/adaptability" and "Predictability". Such characteristics describe the systemic operational effect of the introduction of CPSs (thus, they are characteristics of the CPS-based smart factory).

\subsection{Concluding remarks}

In this section, literature is exploited to achieve the characterization of the CPS-based smart factory. The major characteristics are also synthesized in the schema of Figure 5, which actually synthesizes the answer to the two RQs.

The following table (Table 1) synthesizes and quantifies the results of the literature review. The first column lists the lower-order characteristics analysed in sections 3 and 4 . Therefore, the second column specifies whether such characteristics are (i) the basic ones (i.e. those leading to the schema of Figure 4) or (ii) the completing ones (i.e. those enriching the Figure 4, leading to the schema of Figure 5). Moreover, from left to right, Table 1 shows the progressive aggregations of lower-order characteristics in higher-order ones and then in technological and operations management ones.

From the numerical point of view, Table 1 provides: 
- indication of recognition for each lower-order characteristic, reporting in the third column the total number of times these were addressed as characteristics of CPSs (such figures are also reported in the last rows of the appended Tables A.1 and A.2 which, indeed, count the total times each characteristic were mentioned/recognised);

- indication of recognition for each higher-order characteristic (i.e. C1, C2, .., C9), reporting in the fifth column the total number of references addressing them as characteristics of CPSs (obtained by summing times in which references referred to any of their lower-order characteristics);

- indication of recognition for each group (i.e. integration, intelligence/smartness, cooperation/collaboration), reporting in the seventh and eighth columns the total number (obtained by summing times in which references referred to all their higher-order characteristics) and percentages of references addressing them as characteristics of CPS.

Overall, the last column of Table 1 finally results in an indication of recognition of the two macrogroups - i.e. the characteristics of a CPS (or technological characteristics) and the characteristics of a CPS-based smart factory (or operations management characteristics) - by summing percentages of times literature dealt with their corresponding higher-order characteristics. Such indication provides a measure of their relative weights, thus it is a proxy for their current recognition among researchers. For the sake of clarity, the percentage values reported in the eighth (and tenth) column were calculated diving the aggregated totals corresponding to specific groups (and macro groups) of characteristics by total number of references (e.g. $56,24 \%$ is obtained dividing 248 by 441 ).

(Table 1 here)

Table 1 Summary of characteristics of CPSs according to literature

\begin{tabular}{|c|c|c|c|c|c|c|c|c|c|}
\hline $\begin{array}{l}\text { Lower-order } \\
\text { characteristics }\end{array}$ & $\begin{array}{c}\text { Basic (B)/ } \\
\text { Completing } \\
\text { (C) } \\
\text { characteristics }\end{array}$ & $\begin{array}{c}\text { Total } \\
\text { references }\end{array}$ & $\begin{array}{l}\text { Higher-order } \\
\text { characteristics }\end{array}$ & $\begin{array}{c}\text { Aggregated } \\
\text { totals for } \\
\text { higher-order } \\
\text { characteristics }\end{array}$ & Groups & $\begin{array}{c}\text { Aggregated } \\
\text { totals for } \\
\text { groups }\end{array}$ & $\begin{array}{c}\text { Relative } \\
\text { weights } \\
\text { of groups }\end{array}$ & $\begin{array}{l}\text { Macro } \\
\text { groups }\end{array}$ & $\begin{array}{c}\text { Relative } \\
\text { weights } \\
\text { of macro } \\
\text { groups }\end{array}$ \\
\hline Integration & B & 19 & Integration & 19 & & & & Characteristics & \\
\hline $\begin{array}{l}\text { Complexity and } \\
\text { heterogeneity } \\
\text { encapsulation }\end{array}$ & B & 18 & $\mathrm{C} 1$ & 18 & Integration & 248 & $56,24 \%$ & $\begin{array}{c}\text { of CPSs } \\
\text { (technological } \\
\text { ones) }\end{array}$ & $85,71 \%$ \\
\hline
\end{tabular}




\begin{tabular}{|c|c|c|c|c|c|c|c|c|c|}
\hline Interoperability & B & 15 & \multirow{4}{*}{$\mathrm{C} 2$} & \multirow{4}{*}{96} & & & & & \\
\hline Connectivity & B & 47 & & & & & & & \\
\hline Communication & B & 14 & & & & & & & \\
\hline $\begin{array}{l}\text { Networking } \\
\text { capability }\end{array}$ & B & 20 & & & & & & & \\
\hline $\begin{array}{c}\text { Service } \\
\text { orientation }\end{array}$ & B & 12 & C3 & 12 & & & & & \\
\hline Modularity & B & 14 & \multirow{4}{*}{ C4 } & \multirow{4}{*}{103} & & & & & \\
\hline Autonomy & B & 46 & & & & & & & \\
\hline Self-capabilities & B & 19 & & & & & & & \\
\hline Decentralization & B & 24 & & & & & & & \\
\hline $\begin{array}{c}\text { Intelligence/ } \\
\text { smartness }\end{array}$ & B & 37 & $\begin{array}{c}\text { Intelligence/ } \\
\text { Smartness }\end{array}$ & 37 & \multirow{4}{*}{$\begin{array}{l}\text { Intelligence/ } \\
\text { Smartness }\end{array}$} & \multirow{4}{*}{102} & \multirow{4}{*}{$23,13 \%$} & & \\
\hline Virtualization & B & 20 & \multirow{2}{*}{ C5 } & \multirow{2}{*}{40} & & & & & \\
\hline $\begin{array}{l}\text { Real-time } \\
\text { capability }\end{array}$ & B & 20 & & & & & & & \\
\hline $\begin{array}{c}\text { Computational } \\
\text { capability }\end{array}$ & B & 25 & C6 & 25 & & & & & \\
\hline Cooperation & B & 14 & \multirow{2}{*}{ C7 } & \multirow{2}{*}{28} & \multirow{2}{*}{$\begin{array}{l}\text { Cooperation/ } \\
\text { Collaboration }\end{array}$} & \multirow{2}{*}{28} & \multirow{2}{*}{$6,35 \%$} & & \\
\hline Collaboration & B & 14 & & & & & & & \\
\hline Scalability & C & 7 & \multirow{4}{*}{$\mathrm{C} 8$} & \multirow{4}{*}{49} & \multirow{4}{*}{$\begin{array}{c}\text { Reconfigurability/ } \\
\text { adaptability }\end{array}$} & \multirow{4}{*}{49} & \multirow{4}{*}{$11,11 \%$} & \multirow{6}{*}{$\begin{array}{c}\text { Characteristics } \\
\text { of CPS-based } \\
\text { smart } \\
\text { factories } \\
\text { (operations } \\
\text { management } \\
\text { ones) }\end{array}$} & \multirow{6}{*}{$14,29 \%$} \\
\hline Convertibility & C & 2 & & & & & & & \\
\hline $\begin{array}{c}\text { Dynamic } \\
\text { reconfigurability }\end{array}$ & B & 11 & & & & & & & \\
\hline Adaptability & B & 29 & & & & & & & \\
\hline Diagnosability & C & 5 & \multirow{2}{*}{ C9 } & \multirow{2}{*}{14} & \multirow{2}{*}{ Predictability } & \multirow{2}{*}{14} & \multirow{2}{*}{$3,17 \%$} & & \\
\hline Predictability & C & 9 & & & & & & & \\
\hline Total & B & 441 & & 441 & & 441 & $100 \%$ & & $100 \%$ \\
\hline
\end{tabular}

As synthesized in Table 1, the great part of available contributions is on technological characteristics, especially on the integration characteristics (i.e. the aggregation of C1, C2. C3 and C4). So far, operations management characteristics have gained less attention from literature.

Some of the less cited characteristics, selected based on their semantic meaning, added interesting insights on the most cited ones (as reported in Sections 4.1.1 and 4.1.2). In particular, regarding technological characteristics, (i) the relevance of human presence was stressed and (ii) the computational capability was detailed with the complementary characteristics of sensing, actuation and cognitive capabilities. Moreover, as shown in Figure 5, the enrichment of the characteristics was especially insightful to gain further feedback on operations management characteristics. Above all, a new characteristic $-\mathrm{C} 9$, representing the predictability of the factory - was added. It adds to the other 
two characteristics of a CPS-based smart factory the inclusion of aspects allowing quick reactions to shop-floor contingencies.

\section{Conclusions}

In this paper, based on literature review, the characteristics of CPSs were investigated. As a result, nine characteristics were identified, by aggregating together - based on similarities, complementarities and hierarchical relationships - a high number of characteristics introduced by available literature. Thus, characteristics were classified and synthesized in a comprehensive schema to build future CPS-based smart factories: technological characteristics (i.e. those specifically describing CPSs as technological systems) are building bricks that should be properly combined together to allow practitioners to build CPS-based smart factories which are different from traditional thanks to their characteristics of reconfigurability/adaptability and predictability (referred as operations management characteristics in this article).

Therefore, the schema is a first step to envision how factories will be evolving in a next future, towards CPS-based operations. To move further in this direction, additional research is required.

- The relationships between such characteristics may be explored, so to achieve an understanding of "how" technological characteristics should be exploited by operations managers to benefit from the implementation of CPSs. Indeed, practitioners need to know how new technologies should be combined together and managed to successfully face the current and future scenarios.

- Moreover, the schema may be enriched by means of the reinforcement of extant characteristics as emerged in this work, and the introduction of new characteristics, upcoming in the next years; specifically, the schema may be valuably enriched focusing on the operations management characteristics, which, as shown in Table 1, do not boast a high number of contributions. 
- Finally, an investigation on the effects of both technological and operations management characteristics on business competitiveness may allow glimpsing the benefits of operations management characteristics in terms of business performances. Indeed, the business management perspective is a relevant topic that is outside the scope of this paper, but deserves further research (to this regard, the appended Table A.2 shows that some authors identified characteristics related to business performances, specifically, eight papers referred to "responsiveness" which indeed represents a highly desired performance in the current unpredictable context).

The main limitation of this work is related to the relative novelty of the topic, leading to the rapid evolution of the topic itself and the correspondent development of new theory. For this reason, a future replication of this research may lead to slightly changed results; however, by comparing new results with current results, any replication may actually help framing the evolution of CPS-based smart factories over time.

Concerning future development of the theory, starting from the present paper, it is worth making some reflection.

- The analysis of the less cited characteristics was useful, in the present work, to shed light on the (currently less investigated) operations management characteristics. Looking at future development, such less investigated characteristics can be intended as symptom of newly emerging characteristics that could reinforce in future researches.

- Moreover, industrial practices are essential to provide insightful suggestions on how such evolution will take place: digitalization is an on-going phenomenon in current firms, thus empirical research may provide useful insights on how characteristics of CPSs should be actually concretized in manufacturing firms of different sectors.

Thus, for a complete understanding on how future CPS-based smart factories will develop, empirical research on field should be associated to the theoretical contribution. Indeed, field-based examples on how this digitalization is currently taking place may bring into light insights on 
managerial best practices and/or weaknesses, accelerating the knowledge generation process. Finally, empirical research is also strongly suggested to gain relevant insights on how CPS-based factories will be declined in different sectors: another limitation of this work is the lack of reference to any specific sector and, as this paper has the aim to spread awareness to practitioners, future research may valuably focus on the specification of the characteristics according to different sectors.

\section{Funding}

This research did not receive any specific grant from funding agencies in the public, commercial, or not-for-profit sectors.

\section{References}

[1] Lee H, Ryu K, Cho Y. A Framework of a Smart Injection Molding System Based on Realtime Data. Procedia Manufacturing, vol. 11, 2017, p. 1004-11. doi:10.1016/j.promfg.2017.07.206.

[2] Zhou K, Liu T, Liang L. From cyber-physical systems to Industry 4.0: make future manufacturing become possible. International Journal of Manufacturing Research 2016;11:167-88. doi:10.1504/ijmr.2016.078251.

[3] Angrish A, Starly B, Lee YS, Cohen PH. A flexible data schema and system architecture for the virtualization of manufacturing machines (VMM). Journal of Manufacturing Systems 2017;45:236-47. doi:10.1016/j.jmsy.2017.10.003.

[4] Kulvatunyou B, Ivezic N, Morris KC, Frechette S. Drilling down on Smart Manufacturing enabling composable apps. Manufacturing Letters 2016;10:14-7. doi:10.1016/j.mfglet.2016.08.004.

[5] Leitao P, Barbosa J, Papadopoulou MEC, Venieris IS. Standardization in cyber-physical 
systems: The ARUM case. Proceedings of the IEEE International Conference on Industrial Technology, 2015, p. 2988-93. doi:10.1109/ICIT.2015.7125539.

[6] Mazzolini M, Cavadini FA, Montalbano G, Forni A. Structured Approach to the Design of Automation Systems through IEC 61499 Standard. Procedia Manufacturing, vol. 11, The Author(s); 2017, p. 905-13. doi:10.1016/j.promfg.2017.07.194.

[7] Morgan J, O’Donnell GE. Enabling a ubiquitous and cloud manufacturing foundation with field-level service-oriented architecture. International Journal of Computer Integrated Manufacturing 2017;30:442-58. doi:10.1080/0951192X.2015.1032355.

[8] Etxeberria-Agiriano I, Calvo I, Noguero A, Zulueta E. Configurable cooperative middleware for the next generation of CPS. 2012 9th International Conference on Remote Engineering and Virtual Instrumentation (REV), IEEE; 2012, p. 1-5. doi:10.1109/REV.2012.6293154.

[9] Rosenberg E, Haeusler MH, Araullo R, Gardner N. Smart Architecture-Bots and Industry 4.0 Principles for Architecture. Proceedings of the 33rd eCAADe Conference, vol. 2, 2015, p. $251-9$.

[10] Wan J, Yan H, Suo H, Li F. Advances in cyber-physical systems research. KSII Transactions on Internet and Information Systems 2011;5:1891-908. doi:10.3837/tiis.2011.11.001.

[11] Brettel M, Friederichsen N, Keller M, Rosenberg M. How Virtualization, Decentrazliation and Network Building Change the Manufacturing Landscape: An Industry 4.0 Perspective. International Journal of Mechanical, Aerospace, Industrial, Mechatronic and Manufacturing Engineering 2014;8:37-44. doi:10.1016/j.procir.2015.02.213.

[12] Penas O, Plateaux R, Patalano S, Hammadi M. Multi-scale approach from mechatronic to Cyber-Physical Systems for the design of manufacturing systems. Computers in Industry 2017;86:52-69. doi:10.1016/j.compind.2016.12.001. 
[13] Xu L Da, Xu EL, Li L. Industry 4.0: state of the art and future trends. International Journal of Production Research 2018;56:2941-62. doi:10.1080/00207543.2018.1444806.

[14] Monostori L. Cyber-physical production systems: Roots, expectations and R\&D challenges. Procedia CIRP 2014;17:9-13. doi:10.1016/j.procir.2014.03.115.

[15] Thoben K-D, Wiesner S, Wuest T. "Industrie 4.0" and Smart Manufacturing - A Review of Research Issues and Application Examples. International Journal of Automation Technology 2017;11:4-16. doi:10.20965/ijat.2017.p0004.

[16] Garetti M, Fumagalli L, Negri E. Role of Ontologies for CPS Implementation in Manufacturing. MPER - Management and Production Engineering Review 2015;6:26-32. doi:10.1515/mper-2015-0033.

[17] Lee J, Bagheri B, Kao HA. A Cyber-Physical Systems architecture for Industry 4.0-based manufacturing systems. Manufacturing Letters 2015;3:18-23. doi:10.1016/j.mfglet.2014.12.001.

[18] Lee J, Jin C, Bagheri B. Cyber physical systems for predictive production systems. Production Engineering 2017;11:155-65. doi:10.1007/s11740-017-0729-4.

[19] Nagy J, Oláh J, Erdei E, Máté D, Popp J. The role and impact of industry 4.0 and the internet of things on the business strategy of the value chain-the case of hungary. Sustainability (Switzerland) 2018;10:1-25. doi:10.3390/su10103491.

[20] Lee JH, Do Noh S, Kim HJ, Kang YS. Implementation of cyber-physical production systems for quality prediction and operation control in metal casting. Sensors (Switzerland) 2018;18:1428-44. doi:10.3390/s18051428.

[21] Durach CF, Kembro J, Wieland A. A New Paradigm for Systematic Literature Reviews in 
Supply Chain Management. Journal of Supply Chain Management 2017;53:67-85. doi:10.1111/jscm.12145.

[22] Psarommatis F, May G, Dreyfus P, Kiritsis D. Zero defect manufacturing: state-of-the-art review, shortcomings and future directions in research. International Journal of Production Research 2019;0:1-17. doi:10.1080/00207543.2019.1605228.

[23] Mourtzis D. Simulation in the design and operation of manufacturing systems : state of the art and new trends. International Journal of Production Research 2019;0:1-23. doi:10.1080/00207543.2019.1636321.

[24] Ilsen R, Meissner H, Aurich JC. Optimizing Energy Consumption in a Decentralized Manufacturing System. Journal of Computing and Information Science in Engineering 2017;17:210061-7. doi:10.1115/1.4034585.

[25] Wan J, Chen M, Xia F, Li D, Zhou K. From machine-to-machine communications towards cyber-physical systems. Computer Science and Information Systems 2013;10:1105-28. doi:10.2298/CSIS120326018W.

[26] Bhave A, Krogh BH, Garlan D, Schmerl B. View consistency in architectures for cyberphysical systems. Proceedings - 2011 IEEE/ACM 2nd International Conference on CyberPhysical Systems, ICCPS 2011, 2011, p. 151-60. doi:10.1109/ICCPS.2011.17.

[27] Yuan X, Anumba CJ, Parfitt MK. Review of the Potential for a Cyber-Physical System Approach To Temporary Structures Monitoring. International Journal of Architectural Research 2015;9:26-44.

[28] Li D, Tang H, Wang S, Liu C. A big data enabled load-balancing control for smart manufacturing of Industry 4.0. Cluster Computing 2017;20:1855-64. doi:10.1007/s10586017-0852-1. 
[29] Heiss M, Oertl A, Sturm M, Palensky P, Vielguth S, Nadler F. Platforms for industrial cyberphysical systems integration: Contradicting requirements as drivers for innovation. 2015 Workshop on Modeling and Simulation of Cyber-Physical Energy Systems, MSCPES 2015 Held as Part of CPS Week, 2015. doi:10.1109/MSCPES.2015.7115405.

[30] Byrne G, Dimitrov D, Monostori L, Teti R, Van Houten F, Wertheim R. Biologicalisation: Biological transformation in manufacturing. CIRP Journal of Manufacturing Science and Technology 2018;21:1-32. doi:10.1016/j.cirpj.2018.03.003.

[31] Harrison R, Vera D, Ahmad B. Engineering Methods and Tools for Cyber-Physical Automation Systems. Proceedings of the IEEE, vol. 104, 2016, p. 973-85. doi:10.1109/JPROC.2015.2510665.

[32] Monostori L, Kadar B, Bauernhansl T, Kondoh S, Kumara S, Reinhart G, et al. Cyberphysical systems in manufacturing. CIRP Annals - Manufacturing Technology 2016;65:62141. doi:10.1016/j.cirp.2016.06.005.

[33] Engel G, Greiner T, Seifert S. Ontology-Assisted Engineering of Cyber-Physical Production Systems in the Field of Process Technology. IEEE Transactions on Industrial Informatics 2018;14:2792-802. doi:10.1109/TII.2018.2805320.

[34] Mora H, Colom JF, Gil D, Jimeno-Morenilla A. Distributed computational model for shared processing on Cyber-Physical System environments. Computer Communications 2017;111:68-83. doi:10.1016/j.comcom.2017.07.009.

[35] Iarovyi S, Mohammed WM, Lobov A, Ferrer BR, Lastra JLM. Cyber-Physical Systems for Open-Knowledge-Driven Manufacturing Execution Systems. Proceedings of 5th International Conference on Advanced Manufacturing Engineering and Technologies, 2016, p. 1142-54. doi:10.1109/JPROC.2015.2509498. 
[36] Prause M, Weigand J. Industry 4.0 and Object-Oriented Development : Incremental and Architectural Change. Journal of Technology Management Innovation 2016;11:104-10.

[37] Jirkovsky V, Obitko M, Marik V. Understanding data heterogeneity in the context of cyberphysical systems integration. IEEE Transactions on Industrial Informatics 2017;13:660-7. doi:10.1109/TII.2016.2596101.

[38] Ghobakhloo M. The future of manufacturing industry: a strategic roadmap. Journal of Manufacturing Technology Management 2018;29:910-36. doi:10.1108/JMTM-02-20180057.

[39] Rojas RA, Rauch E, Vidoni R, Matt DT. Enabling Connectivity of Cyber-physical Production Systems: A Conceptual Framework. Procedia Manufacturing 2017;11:822-9. doi:10.1016/j.promfg.2017.07.184.

[40] Ruppert T, Jaskó S, Holczinger T, Abonyi J. Enabling Technologies for Operator 4.0: A Survey. Applied Sciences 2018;8:1650-68. doi:10.3390/app8091650.

[41] Mourtzis D, Vlachou E. A cloud-based cyber-physical system for adaptive shop-floor scheduling and condition-based maintenance. Journal of Manufacturing Systems 2018;47:179-98. doi:10.1016/j.jmsy.2018.05.008.

[42] Contreras JD, Garcia JI, Pastrana JD. Developing of industry 4.0 applications. International Journal of Online Engineering 2017;13:30-47. doi:10.3991/ijoe.v13i10.7331.

[43] Ferrer BR, Iarovyi S, Mohammed WM, Lobov A, Lastra JLM. Exemplifying the Potentials of Web Standards for Automation Control in Manufacturing Systems. International Journal of Simulation -- Systems, Science \& Technology 2016;17:1-12. doi:10.5013/IJSSST.a.17.33.03. 
[44] Liu C, Cao S, Tse W, Xu X. Augmented Reality-assisted Intelligent Window for CyberPhysical Machine Tools. Journal of Manufacturing Systems 2017;44:280-6.

[45] Yu Z, Zhou L, Ma Z, El-Meligy MA. Trustworthiness Modeling and Analysis of Cyberphysical Manufacturing Systems. IEEE Access 2017;5:26076-85. doi:10.1109/ACCESS.2017.2777438.

[46] Gładysz B. An assessment of RFID applications in manufacturing companies. Management and Production Engineering Review 2015;6:33-42. doi:10.1515/mper-2015-0034.

[47] Upasani K, Bakshi M, Pandhare V, Lad BK. Distributed maintenance planning in manufacturing industries. Computers and Industrial Engineering 2017;108:1-14. doi:10.1016/j.cie.2017.03.027.

[48] Tu M, Lim MK, Yang M-F. IoT-based production logistics and supply chain system - part 2 IoT-based cyber-physical system: A framework and evaluation. Industrial Management and Data Systems 2018;118:96-125. doi:10.1108/IMDS-11-2016-0504.

[49] Wang L, Törngren M, Onori M. Current status and advancement of cyber-physical systems in manufacturing. Journal of Manufacturing Systems 2015;37:517-27. doi:10.1016/j.jmsy.2015.04.008.

[50] Isaksson AJ, Harjunkoski I, Sand G. The impact of digitalization on the future of control and operations. Computers and Chemical Engineering 2018;114:122-9. doi:10.1016/j.compchemeng.2017.10.037.

[51] Laird K. Understanding the digital transformation called industry 4.0: Manufacturing today requires more brain than brawn. Plastics Engineering 2017. https://www.thefreelibrary.com/Understanding+the+digital+transformation+called+Industry +4.0\%3A...-a0478974087. 
[52] Tedeschi S, Rodrigues D, Emmanouilidis C, Erkoyuncu RR, Starr A. A cost estimation approach for IoT modular architectures implementation in legacy systems. Procedia Manufacturing 2018;19:103-10. doi:10.1016/j.promfg.2018.01.015.

[53] Rajkumar R, Lee I, Sha L, Stankovic J. Cyber-Physical Systems : The Next Computing Revolution. Design Automation Conference, 2010, p. 731-6. doi:10.1145/1837274.1837461.

[54] Wu F-J, Kao Y-F, Tseng Y-C. From wireless sensor networks towards cyber physical systems. Pervasive and Mobile Computing 2011;7:397-413. doi:10.1016/j.pmcj.2011.03.003.

[55] Wang L, Haghighi A. Combined strength of holons, agents and function blocks in cyberphysical systems. Journal of Manufacturing Systems 2016;40:25-34. doi:10.1016/j.jmsy.2016.05.002.

[56] Cardin O. Classification of cyber-physical production systems applications: Proposition of an analysis framework. Computers in Industry 2019;104:11-21. doi:10.1016/j.compind.2018.10.002.

[57] Woo J, Shin SJ, Seo W, Meilanitasari P. Developing a big data analytics platform for manufacturing systems: architecture, method, and implementation. International Journal of Advanced Manufacturing Technology 2018;99:2193-217. doi:10.1007/s00170-018-2416-9.

[58] Lu Y, Xu X. Cloud-based manufacturing equipment and big data analytics to enable ondemand manufacturing services. Robotics and Computer-Integrated Manufacturing 2019;57:92-102. doi:10.1016/j.rcim.2018.11.006.

[59] Trappey AJC, Trappey C V., Hareesh Govindarajan U, Chuang AC, Sun JJ. A review of essential standards and patent landscapes for the Internet of Things: A key enabler for Industry 4.0. Advanced Engineering Informatics 2017;33:208-29. 
doi:10.1016/j.aei.2016.11.007.

[60] Ali S, Qaisar S Bin, Saeed H, Khan MF, Naeem M, Anpalagan A. Network challenges for cyber physical systems with tiny wireless devices: A case study on reliable pipeline condition monitoring. Sensors (Switzerland) 2015;15:7172-205. doi:10.3390/s150407172.

[61] Lin C-Y, Zeadally S, Chen T-S, Chang C-Y. Enabling Cyber Physical Systems with Wireless Sensor Networking Technologies. International Journal of Distributed Sensor Networks 2012;8:1-21. doi:10.1155/2012/489794.

[62] Setty SS, Yaqoob H, Malik A, Wang KI, Salcic Z, Park H, et al. A Unified Framework for the Design of Distributed Cyber-Physical Systems - Industrial Automation Example. IEEE Access, 2015, p. 996-1002.

[63] Khorrami F, Krishnamurthy P, Karri R. Cybersecurity for Control Systems: A ProcessAware Perspective. IEEE Design \& Test 2016;33:75-83. doi:10.1109/MDAT.2016.2594178.

[64] Wu G, Sun J, Chen J. A survey on the security of cyber-physical systems. Control Theory and Technology 2016;14:2-10. doi:10.1007/s11768-016-5123-9.

[65] Tao F, Qi Q. New IT driven service-oriented smart manufacturing: Framework and characteristics. IEEE Transactions on Systems, Man, and Cybernetics: Systems 2019;49:8191. doi:10.1109/TSMC.2017.2723764.

[66] Stokic D, Scholze S, Decker C, Stobener K. Engineering Methods and Tools for Collaborative Development of Industrial Cyber-Physical Based Products and Services. 12th IEEE International Conference on Industrial Informatics (INDIN), 2014, p. 594-9. doi:10.1109/INDIN.2014.6945580.

[67] Ribeiro L, Hochwallner M. On the Design Complexity of Cyberphysical Production 
Systems. Complexity 2018;2018:1-13. doi:10.1155/2018/4632195.

[68] Krueger BV, Chazoule A, Crosby M, Lasnier A, Pedersen MR, Ieee M, et al. A Vertical and Cyber - Physical Integration of Cognitive Robots in Manufacturing. Proceedings of the IEEE, vol. 104, 2016, p. 1114-27.

[69] Kulvatunyou B, Ivezic N, Srinivasan V. On Architecting and Composing Engineering Information Services to Enable Smart Manufacturing. Journal of Computing and Information Science in Engineering 2016;16:1-31. doi:10.1115/1.4033725.

[70] Wang K. Intelligent Predictive Maintenance (IPdM) system - Industry 4.0 scenario. WIT Transactions on Engineering Sciences 2016;113:259-68. doi:10.2495/IWAMA150301.

[71] Lins RG, Ricardo P, Araujo M De, Corazzim M. In-process machine vision monitoring of tool wear for Cyber-Physical Production Systems 2 . Robotics and Computer Integrated Manufacturing 2020;61:1-17. doi:10.1016/j.rcim.2019.101859.

[72] Fettermann DC, Cavalcante CGS, Almeida TD de, Tortorella GL. How does Industry 4.0 contribute to operations management? Journal of Industrial and Production Engineering 2018;35:255-68. doi:10.1080/21681015.2018.1462863.

[73] Ribeiro L, Bjorkman M. Transitioning from Standard Automation Solutions to CyberPhysical Production Systems: An Assessment of Critical Conceptual and Technical Challenges. IEEE Systems Journal 2018;12:3816-27. doi:10.1109/JSYST.2017.2771139.

[74] Pirvu BC, Zamfirescu CB, Gorecky D. Engineering insights from an anthropocentric cyberphysical system: A case study for an assembly station. Mechatronics 2016;34:147-59. doi:10.1016/j.mechatronics.2015.08.010.

[75] Chen B, Wan J, Shu L, Li P, Mukherjee M, Yin B. Smart Factory of Industry 4.0: Key 
Technologies, Application Case, and Challenges. IEEE Access 2018;6:6505-19. doi:10.1109/ACCESS.2017.2783682.

[76] Scholze S, Barata J, Stokic D. Holistic context-sensitivity for run-time optimization of flexible manufacturing systems. Sensors (Switzerland) 2017;17:1-20. doi:10.3390/s17030455.

[77] Yu Z, Ouyang J, Li S, Peng X. Formal modeling and control of cyber-physical manufacturing systems. Advances in Mechanical Engineering 2017;9:1-12. doi:10.1177/1687814017725472.

[78] Trappey AJC, Trappey C V., Govindarajan UH, Sun JJ, Chuang AC. A Review of Technology Standards and Patent Portfolios for Enabling Cyber-Physical Systems in Advanced Manufacturing. IEEE Access 2016;4:7356-82. doi:10.1109/ACCESS.2016.2619360.

[79] Moghaddam M, Cadavid MN, Kenley CR, Deshmukh A V. Reference architectures for smart manufacturing: A critical review. Journal of Manufacturing Systems 2018;49:215-25. doi:10.1016/j.jmsy.2018.10.006.

[80] Pereira AC, Romero F. A review of the meanings and the implications of the Industry 4.0 concept. Procedia Manufacturing, vol. 13, Elsevier B.V.; 2017, p. 1206-14. doi:10.1016/j.promfg.2017.09.032.

[81] Allenhof S. Implementation of an example application facilitating Industrie 4.0. Automation and Mechatronics Chalmers University of Technology, Gothenburg, Sweden, 2015.

[82] Lee EA. Cyber-Physical Systems - Are Computing Foundations Adequate? Position Paper for NSF Workshop On Cyber-Physical Systems, vol. 1, 2006, p. 1-9. 
[83] Mourtzis D, Vlachou E. Cloud-based cyber-physical systems and quality of services. The TQM Journal 2016;28:704-33.

[84] Babiceanu RF, Seker R. Big Data and virtualization for manufacturing cyber-physical systems: A survey of the current status and future outlook. Computers in Industry 2016;81:128-37. doi:10.1016/j.compind.2016.02.004.

[85] Kritzinger W, Karner M, Traar G, Henjes J, Sihn W, Kritzinger W, et al. Digital Twin in in manufacturing: A categorical literature review and classification. IFAC-PapersOnLine, vol. 51, Elsevier B.V.; 2018, p. 1016-22. doi:10.1016/j.ifacol.2018.08.474.

[86] Sanderson D, Chaplin JC, Ratchev S. Conceptual Framework for Ubiquitous Cyber-Physical Assembly Systems in Airframe Assembly*. IFAC-PapersOnLine 2018;51:417-22. doi:10.1016/j.ifacol.2018.08.331.

[87] Negri E, Fumagalli L, Macchi M. A Review of the Roles of Digital Twin in CPS-based Production Systems. Procedia Manufacturing 2017;11:939-48. doi:10.1016/j.promfg.2017.07.198.

[88] Cimino C, Negri E, Fumagalli L. Computers in Industry Review of digital twin applications in manufacturing. Computers in Industry 2019;113:1-13. doi:10.1016/j.compind.2019.103130.

[89] Mourtzis D, Papakostas N, Mavrikios D, Makris S, Alexopoulos K. The Role Of Simulation In Digital Manufacturing - Applications And Outlook. International Journal of Computer Integrated Manufacturing 2013;28:3-24. doi:10.1080/0951192X.2013.800234.

[90] Hofmann E, Rüsch M. Industry 4.0 and the current status as well as future prospects on logistics. Computers in Industry 2017;89:23-34. doi:10.1016/j.compind.2017.04.002. 
[91] Guzman NHC, Lundteigen MA, Wied M, Kozine I. Conceptualizing the key features of cyber-physical systems in a multi-layered representation for safety and security analysis. Systems Engineering 2019:1-22. doi:10.1002/sys.21509.

[92] Yoon S, Suh S. Manufacturing Information Bus from from the the Perspective of Cyber Physical Manufacturing Systems (CPMS). IFAC PapersOnLine 2016;49:103-8. doi:10.1016/j.ifacol.2016.12.169.

[93] Ji Z, Yanhong Z, Baicun W, Jiyuan Z. Human - Cyber - Physical Systems (HCPSs) in the Context of New-Generation Intelligent Manufacturing. Engineering 2019;5:624-36. doi:10.1016/j.eng.2019.07.015.

[94] Chen T, Tsai HR. Ubiquitous manufacturing: Current practices, challenges, and opportunities. Robotics and Computer-Integrated Manufacturing 2017;45:126-32. doi:10.1016/j.rcim.2016.01.001.

[95] Jakovljevic Z, Vidosav M, Stojadinovic S. Cyber-Physical Manufacturing Systems (CPMS). Proceedings - 5th International Conference on Advanced Manufacturing Engineering and Technologies, 2017, p. 199-214. doi:10.1007/978-3-319-56430-2.

[96] Sunny SMN Al, Liu XF, Shahriar MR. Communication method for manufacturing services in a cyber-physical manufacturing cloud. International Journal of Computer Integrated Manufacturing 2018;31:636-52. doi:10.1080/0951192X.2017.1407446.

[97] Caggiano A. Cloud-based manufacturing process monitoring for smart diagnosis services. International Journal of Computer Integrated Manufacturing 2018;31:612-23. doi:10.1080/0951192X.2018.1425552.

[98] Cheng GJ, Liu LT, Qiang XJ, Liu Y. Industry 4.0 development and application of intelligent manufacturing. Proceedings - 2016 International Conference on Information System and 
Artificial Intelligence, ISAI 2016 2016:407-10. doi:10.1109/ISAI.2016.0092.

[99] Monostori L. Cyber-physical production systems: Roots from manufacturing science and technology. At-Automatisierungstechnik 2015;63:766-76. doi:10.1515/auto-2015-0066.

[100] Lin KJ, Panahi M. A real-time service-oriented framework to support sustainable cyberphysical systems. IEEE International Conference on Industrial Informatics (INDIN), 2010, p. 15-21. doi:10.1155/2012/489794.

[101] Tang H, Li D, Wang S, Dong Z. CASOA: An Architecture for Agent-Based Manufacturing System in the Context of Industry 4.0. IEEE Access 2017;6:12746-54. doi:10.1109/ACCESS.2017.2758160.

[102] Nof SY, Ceroni J, Jeong W, Moghaddam M. Revolutionizing collaboration through e-Work, e-Business, and e-Service. 2015. doi:10.1007/978-3-662-45777-1.

[103] Tran N, Park H, Nguyen Q, Hoang T. Development of a Smart Cyber-Physical Manufacturing System in the Industry 4.0 Context. Applied Sciences 2019;9:1-26. doi:10.3390/app9163325.

[104] Panetto H, Iung B, Ivanov D, Weichhart G, Wang X. Challenges for the cyber-physical manufacturing enterprises of the future. Annual Reviews in Control 2019. doi:10.1016/j.arcontrol.2019.02.002.

[105] Posada J, Toro C, Barandiaran I, Oyarzun D, Stricker D, De Amicis R, et al. Visual Computing as a Key Enabling Technology for Industrie 4.0 and Industrial Internet. IEEE Computer Graphics and Applications 2015;35:26-40. doi:10.1109/MCG.2015.45.

[106] Weyer S, Meyer T, Ohmer M, Gorecky D, Zühlke D. Future Modeling and Simulation of CPS-based Factories: an Example from the Automotive Industry. IFAC-PapersOnLine 
2016;49:97-102. doi:10.1016/j.ifacol.2016.12.168.

[107] Ivanov D, Sokolov B, Ivanova M. Schedule Coordination in Cyber-Physical Supply Networks Industry 4.0. IFAC-PapersOnLine 2016;49:839-44. doi:10.1016/j.ifacol.2016.07.879.

[108] Otto J, Vogel-Heuser B, Niggemann O. Automatic Parameter Estimation for Reusable Software Components of Modular and Reconfigurable Cyber-Physical Production Systems in the Domain of Discrete Manufacturing. IEEE Transactions on Industrial Informatics 2018;14:275-82. doi:10.1109/TII.2017.2718729.

[109] Lanza G, Stricker N, Moser R. Concept of an intelligent production control for global manufacturing in dynamic environments based on rescheduling. 2013 IEEE International Conference on Industrial Engineering and Engineering Management, 2013, p. 315-9. doi:10.1109/IEEM.2013.6962425.

[110] Rama G, Reddy K, Singh H, Hariharan S. Supply chain wide transformation of traditional industry to industry 4.0. Journal of Engineering and Applied Sciences 2016;11:11089-97.

[111] Emmanouilidis C, Pistofidis P, Bertoncelj L, Katsouros V, Fournaris A, Koulamas C, et al. Enabling the human in the loop: Linked data and knowledge in industrial cyber-physical systems. Annual Reviews in Control 2019;47:249-65. doi:10.1016/j.arcontrol.2019.03.004.

[112] Tsai WH, Lu YH. A framework of production planning and control with carbon tax under industry 4.0. Sustainability (Switzerland) 2018;10:1-24. doi:10.3390/su10093221.

[113] Wu D, Terpenny J, Schaefer D. Digital design and manufacturing on the cloud: A review of software and services. Artificial Intelligence for Engineering Design, Analysis and Manufacturing: AIEDAM 2017;31:104-18. doi:10.1017/S0890060416000305. 
[114] Shamim S, Cang S, Yu H, Li Y. Examining the feasibilities of Industry 4.0 for the hospitality sector with the lens of management practice. Energies 2017;10. doi:10.3390/en10040499.

[115] Romero D, Bernus P, Noran O, Stahre J. Advances in Production Management Systems. Initiatives for a Sustainable World. vol. 488. Cham: Springer International Publishing; 2016. doi:10.1007/978-3-319-51133-7_80.

[116] García-Valls M, Calva-Urrego C, de la Puente JA, Alonso A. Adjusting middleware knobs to assess scalability limits of distributed cyber-physical systems. Computer Standards and Interfaces 2017;51:95-103. doi:10.1016/j.csi.2016.11.003.

[117] Facchinetti T, Della Vedova ML. Real-time modeling for direct load control in cyberphysical power systems. IEEE Transactions on Industrial Informatics 2011;7:689-98. doi:10.1109/TII.2011.2166787.

[118] Sun B, Li X, Wan B, Wang C, Zhou X, Chen X. Definitions of predictability for Cyber Physical Systems. Journal of Systems Architecture 2016;63:48-60. doi:10.1016/j.sysarc.2016.01.007.

[119] Kusiak A. Smart Manufacturing. International Journal of Production Research 2018;56:50817. doi:10.1016/B978-0-12-409548-9.10212-X.

[120] Hwang JS. The Fourth Industrial Revolution (Industry 4.0): Intelligent Manufacturing. SMT Magazine 2016;3:616-30.

[121] Alexopoulos K, Sipsas K, Xanthakis E, Makris S, Mourtzis D. An industrial Internet of things based platform for context-aware information services in manufacturing. International Journal of Computer Integrated Manufacturing 2018;31:1111-23. doi:10.1080/0951192X.2018.1500716. 
[122] Allgöwer F, Borges de Sousa J, Kapinski J, Mosterman P, Oehlerking J, Panciatici P, et al. Position paper on the challenges posed by modern applications to cyber-physical systems theory. Nonlinear Analysis: Hybrid Systems 2019;34:147-65. doi:10.1016/j.nahs.2019.05.007.

[123] Ang JH, Goh C, Saldivar AAF, Li Y. Energy-efficient through-life smart design, manufacturing and operation of ships in an industry 4.0 environment. Energies 2017;10:610 22. doi:10.3390/en10050610.

[124] Beregi R, Pedone G, Mezgár I. A novel fluid architecture for cyber-physical production systems. International Journal of Computer Integrated Manufacturing 2019;32:340-51. doi:10.1080/0951192X.2019.1571239.

[125] Bibby L, Dehe B. Defining and assessing industry 4.0 maturity levels-case of the defence sector. Production Planning and Control 2018;29:1030-43. doi:10.1080/09537287.2018.1503355.

[126] Bohács G, Rinkács A. Development of an ontology-driven, component based framework for the implementation of adaptiveness in a Jellyfish-type simulation model. Journal of Ambient Intelligence and Smart Environments 2017;9:361-74. doi:10.3233/AIS-170437.

[127] Bonci A, Pirani M, Longhi S. A Database-Centric Framework for the Modeling, Simulation, and Control of Cyber-Physical Systems in the Factory of the Future. Journal of Intelligent Systems 2017;27:659-79. doi:10.1515/jisys-2016-0281.

[128] Brödner P. "Super-intelligent” machine: technological exuberance or the road to subjection. AI and Society 2018;33:335-46. doi:10.1007/s00146-017-0731-6.

[129] Chang D, Chen C-H. Digital design and manufacturing of wood head golf club in a cyber physical environment. Industrial Management \& Data Systems 2017;117:648-71. 
doi:https://doi.org/10.1108/IMDS-07-2016-0280.

[130] Chen Y. Integrated and Intelligent Manufacturing: Perspectives and Enablers. Engineering 2017;3:588-95. doi:10.1016/J.ENG.2017.04.009.

[131] Cheng Y, Zhang Y, Ji P, Xu W, Zhou Z, Tao F. Cyber-physical integration for moving digital factories forward towards smart manufacturing: a survey. The International Journal of Advanced Manufacturing Technology 2018;97:1209-21.

[132] Cozmiuc D, Petrisor I. Industrie 4.0 by Siemens: Steps Made Next. Journal of Cases on Information Technology 2018;20:30-48. doi:10.4018/JCIT.2018040103.

[133] Cruz Salazar LA, Ryashentseva D, Lüder A, Vogel-Heuser B. Cyber-physical production systems architecture based on multi-agent's design pattern-comparison of selected approaches mapping four agent patterns. The International Journal of Advanced Manufacturing Technology 2019. doi:10.1007/s00170-019-03800-4.

[134] Culler D, Long J. A Prototype Smart Materials Warehouse Application Implemented using Custom Mobile Robots and Open Source Vision Technology Developed using EmguCV. Procedia Manufacturing 2016;5:1092-106. doi:10.1016/j.promfg.2016.08.080.

[135] Ding K, Jiang P. Incorporating social sensors, cyber-physical system nodes, and smart products for personalized production in a social manufacturing environment. Journal of ENGINEERING MANUFACTURE 2017:1-16. doi:10.1177/0954405417716728.

[136] Dumitrache I, Caramihai SI, Moisescu MA. A Perceptive Interface for Intelligent. Sensors 2019;19:1-20.

[137] Fumagalli L, Negri E, Severa O, Balda P, Rondi E. Distributed control via modularized CPS architecture Lessons learnt from an industrial case study. IFAC-PapersOnLine, vol. 51, 
Elsevier B.V.; 2018, p. 803-8. doi:10.1016/j.ifacol.2018.08.417.

[138] Gaham M, Bouzouia B, Achour N. Human-in-the-Loop Cyber-Physical Production Systems Control (HiLCP2sC): A Multi-objective Interactive Framework Proposal. Studies in Computational Intelligence - Service Orientation in Holonic and Multi-agent Manufacturing, vol. 594, 2015, p. 315-21. doi:10.1007/978-3-319-30337-6.

[139] Ghadimi P, Wang C, Lim MK, Heavey C. Intelligent sustainable supplier selection using multi-agent technology: Theory and application for Industry 4.0 supply chains. Computers and Industrial Engineering 2018;127:588-600. doi:10.1016/j.cie.2018.10.050.

[140] Grundstein S, Freitag M, Scholz-Reiter B. A new method for autonomous control of complex job shops - Integrating order release, sequencing and capacity control to meet due dates. Journal of Manufacturing Systems 2017;42:11-28. doi:10.1016/j.jmsy.2016.10.006.

[141] Harrison R, Vera D, Ahmad B. Engineering the smart factory. Chinese Journal of Mechanical Engineering 2016;29:1046-51. doi:10.3901/cjme.2016.0908.109.

[142] Hozdić E. Smart Factory for Industry 4.0: a review. International Journal of Modern Manufacturing Technologies 2015;7:28-35.

[143] Hu Y, Zhou X. CPS-Agent oriented construction and implementation for cyber physical systems. IEEE Access 2018;6:57631-42. doi:10.1109/ACCESS.2018.2873751.

[144] Huang Z, Kim J, Sadri A, Dowey S, Dargusch MS. Industry 4.0: Development of a multiagent system for dynamic value stream mapping in SMEs. Journal of Manufacturing Systems 2019;52:1-12. doi:10.1016/j.jmsy.2019.05.001.

[145] Jakovljevic Z, Mitrovic S, Ivanova M. Cyber physical production systems: An IEC 61499 Perspective. Proceedings of 5th International Conference on Advanced Manufacturing 
Engineering and Technologies, Lecture Notes in Mechanical Engineering, 2017, p. 27-39.

[146] Jiang P, Ding K, Leng J. Towards a cyber-physical-social-connected and service-oriented manufacturing paradigm : Social Manufacturing. Manufacturing Letters 2016;7:15-21. doi:10.1016/j.mfglet.2015.12.002.

[147] Jiang Z, Jin Y, Mingcheng E, Li Q. Distributed Dynamic Scheduling for Cyber-Physical Production Systems Based on a Multi-Agent System. IEEE Access 2017;6:1855-69. doi:10.1109/ACCESS.2017.2780321.

[148] Jones AT, Romero D, Wuest T. Modeling agents as joint cognitive systems in smart manufacturing systems. Manufacturing Letters 2018;17:6-8. doi:10.1016/j.mfglet.2018.06.002.

[149] Kang HS, Lee JY, Noh S Do. A dynamic processing methodology of manufacturing data for the automated throughput analysis in cyber-physical production environment. Concurrent Engineering Research and Applications 2019;27:155-69. doi:10.1177/1063293X19842264.

[150] Kao H-A, Jin W, Siegel D, Lee J. A Cyber Physical Interface for Automation SystemsMethodology and Examples. Machines 2015;3:93-106. doi:10.3390/machines3020093.

[151] Khalid A, Kirisci P, Ghrairi Z, Thoben K-D, Pannek J. A methodology to develop collaborative robotic cyber physical systems for production environments. Logistics Research 2016;9:1-15. doi:10.1007/s12159-016-0151-x.

[152] Kolberg D, Knobloch J, Zuhlke D. Towards a lean automation interface for workstations. International Journal of Production Research 2017;55:2845-56. doi:10.1080/00207543.2018.1223384.

[153] Krishnamurthy R, Cecil J. A next-generation IoT-based collaborative framework for 
electronics assembly. International Journal of Advanced Manufacturing Technology 2018;96:39-52. doi:10.1007/s00170-017-1561-x.

[154] Latorre-Biel JI, Faulín J, Juan AA, Jiménez-Macías E. Petri Net Model of a Smart Factory in the Frame of Industry 4.0. IFAC-PapersOnLine 2018;51:266-71. doi:10.1016/j.ifacol.2018.03.046.

[155] Lee H, Kim T. Prototype of IoT enabled smart factory. ICIC Express Letters, Part B: Applications 2016;7:955-60.

[156] Lee J, Bagheri B, Jin C. Introduction to cyber manufacturing. Manufacturing Letters 2016;8:11-5. doi:10.1016/j.mfglet.2016.05.002.

[157] Leitão P, Rodrigues N, Barbosa J, Turrin C, Pagani A. Intelligent products: The grace experience. Control Engineering Practice 2015;42:95-105. doi:10.1016/j.conengprac.2015.05.001.

[158] Leng J. Digital twin-driven manufacturing cyber-physical system for parallel controlling of smart workshop. Journal of Ambient Intelligence and Humanized Computing 2019;0. doi:10.1007/s12652-018-0881-5.

[159] Liu C, Jiang P. Social factory as a production node of social manufacturing. Proceedings of the Institution of Mechanical Engineers, Part C: Journal of Mechanical Engineering Science 2019;233:5144-60. doi:10.1177/0954406219840680.

[160] Liu Y, Xu X. Industry 4.0 and Cloud Manufacturing: A Comparative Analysis. Journal of Manufacturing Science and Engineering 2017;139:034701-8. doi:10.1115/1.4034667.

[161] Liu C, Vengayil H, Zhong RY, Xu X. A systematic development method for cyber-physical machine tools. Journal of Manufacturing Systems 2018;48:13-24. 
doi:10.1016/j.jmsy.2018.02.001.

[162] Liu C, Vengayil H, Lu Y, Xu X. A Cyber-Physical Machine Tools Platform using OPC UA and MTConnect. Journal of Manufacturing Systems 2019;51:61-74. doi:10.1016/j.jmsy.2019.04.006.

[163] Luo RC, Kuo CW. Intelligent seven-DoF robot with dynamic obstacle avoidance and 3-D object recognition for industrial cyber-physical systems in manufacturing automation. Proceedings of the IEEE 2016;104:1102-13. doi:10.1109/JPROC.2015.2508598.

[164] Miranda J, Pérez-Rodríguez R, Borja V, Wright PK, Molina A. Integrated Product, Process and Manufacturing System Development Reference Model to develop Cyber-Physical Production Systems - The Sensing, Smart and Sustainable Microfactory Case Study. IFACPapersOnLine 2017;50:13065-71. doi:10.1016/j.ifacol.2017.08.2006.

[165] Morel G, Pereira CE, Nof SY. Historical survey and emerging challenges of manufacturing automation modeling and control: A systems architecting perspective. Annual Reviews in Control 2019. doi:10.1016/J.ARCONTROL.2019.01.002.

[166] Morozov D, Lezoche M, Panetto H. Multi-paradigm modelling of Cyber-Physical Systems. IFAC-PapersOnLine 2018;51:1385-90. doi:10.1016/j.ifacol.2018.08.334.

[167] Neugebauer R, Ihlenfeldt S, Schliebmann U, Hellmich A, Noack M. A new generation of production with Cyber-Physical Systems - enabling the biological transformation in Manufacturing. Journal of Machine Engineering 2019;19:5-15.

[168] Oborski P. Integrated monitoring system of production processes. Management and Production Engineering Review 2016;7:86-96. doi:10.1515/mper-2016-0039.

[169] Ocker F, Kovalenko I, Barton K, Tilbury D, Vogel-heuser B. A Framework for Automatic 
Initialization of Multi-Agent Production Systems Using Semantic Web Technologies. IEEE Robotics and Automation Letters 2019;4:4330-7. doi:10.1109/LRA.2019.2931825.

[170] Peres RS, Dionisio Rocha A, Leitao P, Barata J. IDARTS - Towards intelligent data analysis and real-time supervision for industry 4.0. Computers in Industry 2018;101:138-46. doi:10.1016/j.compind.2018.07.004.

[171] Peruzzini M, Pellicciari M. A framework to design a human-centred adaptive manufacturing system for aging workers. Advanced Engineering Informatics 2017;33:330-49. doi:10.1016/j.aei.2017.02.003.

[172] Qu YJ, Ming XG, Liu ZW, Zhang XY, Hou ZT. Smart manufacturing systems: state of the art and future trends. International Journal of Advanced Manufacturing Technology 2019:3751-68. doi:10.1007/s00170-019-03754-7.

[173] Rojas RA, Rauch E. From a literature review to a conceptual framework of enablers for smart manufacturing control. International Journal of Advanced Manufacturing Technology 2019. doi:10.1007/s00170-019-03854-4.

[174] Sanislav T, Miclea L. Cyber-Physical Systems - Concept, Challenges and Research Areas. Journal of Control Engineering and Applied Informatics 2012;14:28-33.

[175] Schuhmacher J, Baumung W, Hummel V. An intelligent bin system for decentrally controlled intralogistics systems in context of Industrie 4.0. Procedia Manufacturing 2017;9:135-42.

[176] Shafiq SI, Sanin C, Toro C, Szczerbicki E. Virtual engineering object (VEO): Toward experience-based design and manufacturing for industry 4.0. Cybernetics and Systems 2015;46:35-50. doi:10.1080/01969722.2015.1007734. 
[177] Shafiq SI, Sanin C, Szczerbicki E, Toro C. Virtual Engineering Factory: Creating Experience Base for Industry 4.0. Cybernetics and Systems 2016;47:32-47. doi:10.1080/01969722.2016.1128762.

[178] Song Z, Sun Y, Wan J, Liang P. Data quality management for service-oriented manufacturing cyber-physical systems. Computers and Electrical Engineering 2017;64:3444. doi:10.1016/j.compeleceng.2016.08.010.

[179] Song Z, Moon Y. Performance analysis of CyberManufacturing Systems. Proceedings of the Institution of Mechanical Engineers, Part B: Journal of Engineering Manufacture 2019;233:1362-76. doi:10.1177/0954405417706996.

[180] Sun Y, Zhou X, Yang G. Location Sensitive Multi-Task Oriented Service. International Journal of Innovative Computing, Information and Control 2018;14:1057-77.

[181] Tang D, Zheng K, Zhang H, Zhang Z, Sang Z, Zhang T, et al. Using autonomous intelligence to build a smart shop floor. International Journal of Advanced Manufacturing Technology 2018;94:1597-606. doi:10.1007/s00170-017-0459-y.

[182] Tao F, Qi Q, Wang L, Nee AYC. Digital Twins and Cyber-Physical Systems toward Smart Manufacturing and Industry 4.0: Correlation and Comparison. Engineering 2019:1-9. doi:10.1016/j.eng.2019.01.014.

[183] Tarallo A, Mozzillo R, Di Gironimo G, De Amicis R. A cyber-physical system for production monitoring of manual manufacturing processes. International Journal on Interactive Design and Manufacturing 2018;12:1235-41. doi:10.1007/s12008-018-0493-5.

[184] Tavcar J, Horvath I. A review of the principles of designing smart cyber-physical systems for run-time adaptation: Learned lessons and open issues. IEEE Transactions on Systems, Man, and Cybernetics: Systems 2019;49:145-58. doi:10.1109/TSMC.2018.2814539. 
[185] Terziyan V, Gryshko S, Golovianko M. Patented intelligence: Cloning human decision models for Industry 4.0. Journal of Manufacturing Systems 2018;48:204-17. doi:10.1016/j.jmsy.2018.04.019.

[186] Thramboulidis K, Christoulakis F. UML4IoT-A UML-based approach to exploit IoT in cyber-physical manufacturing systems. Computers in Industry 2016;82:259-72. doi:10.1016/j.compind.2016.05.010.

[187] Tuptuk N, Hailes S. Security of smart manufacturing systems. Journal of Manufacturing Systems 2018;47:93-106. doi:10.1016/j.jmsy.2018.04.007.

[188] Uhlmann E, Hohwieler E, Geisert C. Intelligent production systems in the era of industrie 4.0 - changing mindsets and business models. Journal of Machine Engineering 2017;17:5-25.

[189] Wang Z, Song H, Watkins DW, Ong KG, Xue P, Yang Q, et al. Cyber-physical systems for water sustainability: Challenges and opportunities. IEEE Communications Magazine 2015;53:216-22. doi:10.1109/MCOM.2015.7105668.

[190] Wang S, Wan J, Zhang D, Li D, Zhang C. Towards smart factory for industry 4.0: a selforganized multi-agent system with big data based feedback and coordination. Computer Networks 2016;101:158-68. doi:10.1016/j.comnet.2015.12.017.

[191] Wang L. An overview of internet-enabled cloud-based cyber manufacturing. Transactions of the Institute of Measurement and Control 2017;39:388-97. doi:10.1177/0142331216687817.

[192] Wang W, Zhang Y, Zhong RY. A proactive material handling method for CPS enabled shopfloor. Robotics and Computer-Integrated Manufacturing 2020;61:101849. doi:10.1016/j.rcim.2019.101849.

[193] Wu M, Moon YB. Intrusion Detection System for Cyber-Manufacturing System. Journal of 
Manufacturing Science and Engineering 2019;141:0310071-9. doi:10.1115/1.4042053.

[194] Xu X. Machine Tool 4.0 for the new era of manufacturing. International Journal of Advanced Manufacturing Technology 2017;92:1893-900. doi:10.1007/s00170-017-0300-7.

[195] Xu X, Hua Q. Industrial Big Data Analysis in Smart Factory: Current Status and Research Strategies. IEEE Access 2017;5:17543-51. doi:10.1109/ACCESS.2017.2741105.

[196] Xu L Da, Duan L. Big data for cyber physical systems in industry 4.0: a survey. Enterprise Information Systems 2019;13:148-69. doi:10.1080/17517575.2018.1442934.

[197] Xu H, Yu W, Griffith D, Golmie N. A Survey on Industrial Internet of Things: A CyberPhysical Systems Perspective. IEEE Access 2018;6:78238-59. doi:10.1109/ACCESS.2018.2884906.

[198] Yao B, Zhou Z, Wang L, Xu W, Yan J, Liu Q. A function block based cyber-physical production system for physical human-robot interaction. Journal of Manufacturing Systems 2018;48:12-23. doi:10.1016/j.jmsy.2018.04.010.

[199] Yu C, Xu X, Lu Y. Computer-Integrated Manufacturing, Cyber-Physical Systems and Cloud Manufacturing - Concepts and relationships. Manufacturing Letters 2015;6:5-9. doi:10.1016/j.mfglet.2015.11.005.

[200] Zhang Y, Qian C, Lv J, Liu Y. Agent and Cyber-Physical System Based Self-Organizing and Self-Adaptive Intelligent Shopfloor. IEEE Transactions on Industrial Informatics 2017;13:737-47. doi:10.1109/TII.2016.2618892.

[201] Zheng P, wang H, Sang Z, Zhong RY, Liu Y, Liu C, et al. Smart manufacturing systems for Industry 4.0: Conceptual framework, scenarios, and future perspectives. Frontiers of Mechanical Engineering 2018;13:137-50. doi:10.1007/s11465-018-0499-5. 
[202] Zhou Z, Hu J, Liu Q, Lou P, Yan J, Li W. Fog computing-based cyber-physical machine tool system. IEEE Access 2018;6:44580-90. doi:10.1109/ACCESS.2018.2863258.

[203] Bonci A, Pirani M, Longhi S. Tiny Cyber-Physical Systems for Performance Improvement in the Factory of the Future. IEEE Transactions on Industrial Informatics 2019;15:1598-608. doi:10.1109/TII.2018.2855747.

[204] Mittal S, Khan MA, Romero D, Wuest T. Smart manufacturing: Characteristics, technologies and enabling factors. Proceedings of the Institution of Mechanical Engineers, Part B: Journal of Engineering Manufacture 2019;233:1342-61. doi:10.1177/0954405417736547.

[205] Stern H, Becker T. Concept and Evaluation of a Method for the Integration of Human Factors into Human-Oriented Work Design in Cyber-Physical Production Systems. Sustainability 2019;11:1-33. doi:10.3390/su11164508.

\section{Appendix}

(Tables A.1 and A.2 here)

Table A.1 Characteristics of CPSs according to literature (most cited characteristics)

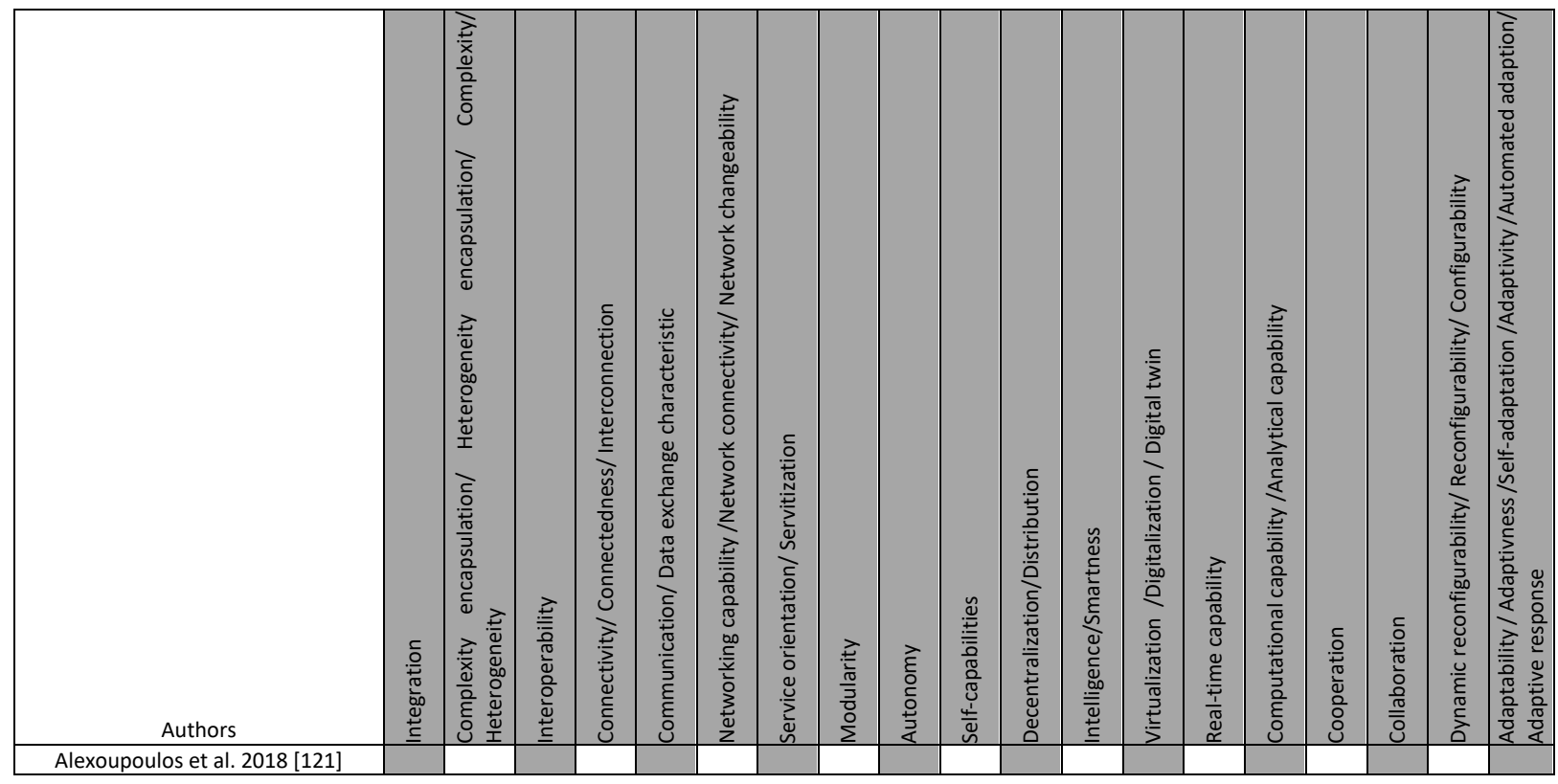




\begin{tabular}{|c|c|c|c|c|c|c|c|c|c|c|c|c|c|c|c|c|c|c|c|}
\hline Allgöwer et al. 2019 [122] & & & & $x$ & & & & & $x$ & & $\mathrm{x}$ & & & & & & $\mathrm{x}$ & & $\mathrm{x}$ \\
\hline Ang et al. 2017 [123] & & & & & & & & & $x$ & & & & & & & & & & \\
\hline Beregi, Pedone and Mezgár 2019 [124] & & & & & & $x$ & & & & & & & & & $x$ & & & & \\
\hline Bibby and Dehe 2018 [125] & & & & $\mathrm{X}$ & & & & & & & & & & & & & & & \\
\hline Bohacs and Rinkacs 2017 [126] & & & & & & & & & $x$ & & $\mathrm{x}$ & & & & & & & & \\
\hline Bonci, Pirani and Longhi 2017 [127] & & & & & & & & & & $\mathrm{x}$ & & & & & & & & & \\
\hline Brodner $2018[128]$ & & & & & & & & & $\mathrm{x}$ & & & $x$ & & & & & & & \\
\hline Byrne et al. 2018 [30] & & $\mathrm{x}$ & & & & & & & & & & & & & & & & & \\
\hline Cardin $2019[56]$ & & & & $\mathrm{x}$ & $\mathrm{X}$ & & & & & & & $\mathrm{X}$ & & & $\mathrm{x}$ & & & & \\
\hline Carreras Guzman et al. 2019 [91] & & & & & & & & & & & & & & $\mathrm{x}$ & & & & & \\
\hline Chang and Chen 2017 [129] & & & $\mathrm{x}$ & $\mathrm{x}$ & & & & & & & & & & & & & $\mathrm{x}$ & & \\
\hline Chen 2017 [130] & $\mathrm{x}$ & & & $\mathrm{X}$ & & & & & & & & $x$ & & & $x$ & & $x$ & & \\
\hline Chen and Tsai 2017 [94] & & & $\mathrm{x}$ & & & & & & & & & & & & & & & & \\
\hline Chen et al. 2018 [75] & $\mathrm{x}$ & $\mathrm{x}$ & & $\mathrm{x}$ & & & & $\mathrm{x}$ & $\mathrm{x}$ & & $\mathrm{x}$ & $\mathrm{x}$ & & & & & $\mathrm{x}$ & $\mathrm{x}$ & \\
\hline Cheng et al. $2018[131]$ & $\mathrm{x}$ & & & $\mathrm{X}$ & & & & & & & & & $\mathrm{x}$ & & & & & & \\
\hline Cimino, Negri and Fumagalli 2019 [88] & & & & & & & & & & & & & $x$ & & & & & & \\
\hline $\begin{array}{c}\text { Contreras, Garcia and Pastrana } 2017 \\
{[42]}\end{array}$ & & & & & & & & & & & & $\mathrm{x}$ & & & & & & & \\
\hline Cozmiuc and Petrisor 2018 [132] & & $\mathrm{X}$ & & & & & & & & & & & & & & & & & \\
\hline Cruz Salazar et al. 2019 [133] & & & & & & & & & & & & & & & & & & $\mathrm{x}$ & $x$ \\
\hline Culler and Long 2016 [134] & & & & & $x$ & & & & $x$ & $x$ & & & & & $x$ & & $x$ & & \\
\hline Ding and Jiang 2017 [135] & $\mathrm{x}$ & & & $\mathrm{X}$ & $\mathrm{x}$ & & $x$ & & $\mathrm{x}$ & $\mathrm{x}$ & $\mathrm{x}$ & & & & & & & & \\
\hline Dumitrache et al. 2019 [136] & & & & $\mathrm{X}$ & & & & & & & $\mathrm{x}$ & & & & & & & & \\
\hline $\begin{array}{c}\text { Facchinetti and Della Vedova } 2011 \\
\text { [117] }\end{array}$ & $x$ & & & & & & & & & & & & & & & & & & \\
\hline Fettermann et al. 2018 [72] & & & & $\mathrm{X}$ & & & & & $\mathrm{x}$ & & & & & & & $\mathrm{x}$ & & & \\
\hline Fumagalli et al. 2018 [137] & & & & & & & & $\mathrm{x}$ & & & & & & & & & & & \\
\hline $\begin{array}{c}\text { Gaham, Bouzouia and Achour } 2015 \\
{[138]}\end{array}$ & & & & & & & & & $x$ & & & $\mathrm{x}$ & & & & & $\mathrm{x}$ & & \\
\hline Garetti, Fumagalli and Negri 2015 [16] & & $\mathrm{x}$ & & & & $\mathrm{x}$ & & & & & & & & & & & & & \\
\hline Ghadimi et al. 2019 [139] & & & & $\mathrm{x}$ & & & & & & & $x$ & & & $\mathrm{x}$ & & & & & \\
\hline Ghobakhloo 2018 [38] & $x$ & & & $\mathrm{x}$ & & & $x$ & $\mathrm{x}$ & & & $\mathrm{x}$ & $\mathrm{x}$ & $\mathrm{x}$ & & $\mathrm{x}$ & & & & \\
\hline Gladysz $2015[46]$ & & & & & $\mathrm{x}$ & & & & & & & & & & $\mathrm{x}$ & & & & \\
\hline $\begin{array}{l}\text { Grundstein, Freitag and Scholz-Reiter } \\
2017 \text { [140] }\end{array}$ & & & & & & $\mathrm{x}$ & & & & $x$ & & $\mathrm{x}$ & & & & & & & \\
\hline Harrison, Vera and Ahmad 2016a [31] & & $x$ & & & & & & $x$ & & & & & & & & & & & \\
\hline $\begin{array}{c}\text { Harrison, Vera and Ahmad 2016b } \\
{[141]}\end{array}$ & $x$ & & & $x$ & & & & & & & & & & & & & $\mathrm{x}$ & & \\
\hline Hofmann and Rusch 2017 [90] & & & & $\mathrm{x}$ & & & & & & $x$ & & & $x$ & & & & & & $\mathrm{x}$ \\
\hline Hozdic 2015 [142] & & & & & & & & & $\mathrm{x}$ & & & & & & & $\mathrm{x}$ & & $\mathrm{x}$ & \\
\hline Hu and Zhou 2018 [143] & & & & & & & & & $\mathrm{x}$ & & & & & & & & & & \\
\hline Huang et al. 2019 [144] & & & & & & & & $\mathrm{x}$ & & & $\mathrm{x}$ & & $x$ & $\mathrm{x}$ & & & & & \\
\hline Hwang 2016 [120] & & & & & & & & & & & & & & & & & & & \\
\hline larovyi et al. 2016 [35] & & & & & & & & & & & & & & & & & & & $\mathrm{x}$ \\
\hline Ilsen, Meissner and Aurich 2017 [24] & & & & & & & & & $\mathrm{x}$ & $\mathrm{X}$ & $\mathrm{x}$ & & & & & & & & \\
\hline $\begin{array}{c}\text { Ivanov, Sokolov and Ivanova } 2016 \\
{[107]}\end{array}$ & & & & & & & & & & & $x$ & & & & & & & & \\
\hline $\begin{array}{c}\text { Jakovljevic, Mitrovic and Pajic } 2017 \\
{[145]}\end{array}$ & & & & & $\mathrm{x}$ & & & & & & & & & $x$ & $x$ & & & & \\
\hline Jiang, Ding and Leng 2016 [146] & & & & & & & $\mathrm{x}$ & & & & & & & & & & & & \\
\hline Jiang et al. $2017[147]$ & & $x$ & & & & & & & $x$ & & $\mathrm{x}$ & $x$ & & & & & & & \\
\hline Jones, Romero and Wuest 2018 [148] & & & $\mathrm{X}$ & $\mathrm{x}$ & & & & & & & & $\mathrm{x}$ & & & & & & & $\mathrm{X}$ \\
\hline Kang, Lee and Noh 2019 [149] & & & & & & & & & & & & $\mathrm{x}$ & & $\mathrm{x}$ & & & & & \\
\hline Kao et al. 2015 [150] & & & & & & & & & & $\mathrm{x}$ & & & $x$ & & & & & & \\
\hline Khalid et al. 2016 [151] & & & & & & & & & $\mathrm{x}$ & $\mathrm{x}$ & & & & & & & & & $x$ \\
\hline $\begin{array}{c}\text { Kolberg, Knobloch and Zuhlke } 2017 \\
{[152]}\end{array}$ & & & & & & & & & & & & & & & & & & & $x$ \\
\hline Krishnamurthy and Cecil 2018 [153] & & $\mathrm{X}$ & & & & $\mathrm{X}$ & & & & & & & & & $x$ & & $\mathrm{x}$ & & \\
\hline Krueger et al. 2016 [68] & & & & $\mathrm{x}$ & & & & & $\mathrm{x}$ & & & & & & & $\mathrm{x}$ & & & \\
\hline Kusiak 2018 [119] & $\mathrm{x}$ & & $\mathrm{x}$ & $\mathrm{x}$ & & & & & & & & & $\mathrm{x}$ & & & & $x$ & & \\
\hline Latorre-Biel et al. 2018 [154] & & & & $\mathrm{x}$ & $x$ & & & & & & & & $\mathrm{x}$ & & $\mathrm{x}$ & & & & \\
\hline Lee, Bagheri and Kao 2015 [17] & & & & $\mathrm{x}$ & & & & & & & & $\mathrm{x}$ & & & $\mathrm{x}$ & & & & \\
\hline Lee and Kim 2016 [155] & & $\mathrm{x}$ & & $\mathrm{X}$ & & & & & & & & & & & & & & & \\
\hline Lee, Bagheri and Jin 2016 [156] & $\mathrm{x}$ & & $\mathrm{x}$ & & & & & & & & & & & & & & & & \\
\hline Lee, Ryu and Cho 2017 [1] & & & $\mathrm{x}$ & & & & $\mathrm{x}$ & $\mathrm{x}$ & & & $\mathrm{x}$ & & $\mathrm{x}$ & $\mathrm{x}$ & & & & & \\
\hline Leitao et al. 2015b [157] & & & & & & & & & & & & & & & $\mathrm{X}$ & & & & \\
\hline Leng et al. 2019 [158] & & & & & $\mathrm{x}$ & & & & & & & & & & $\mathrm{x}$ & & & & \\
\hline \begin{tabular}{|l|} 
Li et al. $2017[28]$ \\
\end{tabular} & & & & & $\mathrm{x}$ & & & & & $\mathrm{x}$ & & & & & & & & & \\
\hline Lins, de Araujo and Corazzim 2019 [71] & & & & & & & & $\mathrm{x}$ & & & & & & & & & & & \\
\hline Liu and Jiang 2019 [159] & & & & & & & & & $x$ & & & $\mathrm{x}$ & & & & & & & \\
\hline Liu and Xu. $2017[160]$ & $\mathrm{x}$ & & & & & $\mathrm{X}$ & & & & & & $\mathrm{x}$ & & & & & & & \\
\hline Liu et al. 2017 [44] & & & & $\mathrm{x}$ & & $\mathrm{x}$ & & & & & & $\mathrm{x}$ & & & $\mathrm{x}$ & & & & $x$ \\
\hline Liu et al. 2018 [161] & & & & $x$ & & $x$ & & & $\mathrm{X}$ & & & $x$ & $x$ & $x$ & $\mathrm{x}$ & & & & \\
\hline Liu et al. 2019 [162] & & & & & & $\mathrm{x}$ & & & & & & $\mathrm{X}$ & & $x$ & & & & & $x$ \\
\hline Lu and Xu 2019 [58] & & & & $\mathrm{x}$ & & & & & & & & $x$ & & & & & & & \\
\hline Luo and Kuo 2016 [163] & & $\mathrm{x}$ & & & & & $x$ & & $x$ & & & & & & & & & & \\
\hline Miranda et al. 2017 [164] & & & & & & & & & $\bar{x}$ & & & & & & & $\bar{x}$ & & & \\
\hline Moghaddam et al. 2018 [79] & & & $x$ & $\mathrm{x}$ & & & $x$ & & $x$ & & & & $x$ & & & & & & \\
\hline Monostori 2015 [99] & & & & $\mathrm{x}$ & & & & & $x$ & & & & & & & $\mathrm{x}$ & & & \\
\hline
\end{tabular}




\begin{tabular}{|c|c|c|c|c|c|c|c|c|c|c|c|c|c|c|c|c|c|c|c|}
\hline Monostori et al. 2016 [32] & & & & $\mathrm{x}$ & & & & & & & & $\mathrm{x}$ & & & $\mathrm{x}$ & & & & \\
\hline Mora et al. 2017 [34] & & $x$ & & & & $x$ & & & & & & & & $x$ & $x$ & & $x$ & & \\
\hline Morel, Pereira and Nof 2019 [165] & & & & & & & $x$ & & $x$ & & & & & & & & & & \\
\hline $\begin{array}{l}\text { Morozov, Lezoche and Panetto } 2018 \\
\text { [166] }\end{array}$ & & & & & $\mathrm{x}$ & & & & $\mathrm{x}$ & & & & & & & & & & \\
\hline Mourtzis and Vlachou 2018 [41] & & & $\mathrm{x}$ & $\mathrm{x}$ & & & & & & & & & & & & & & & \\
\hline Neugebauer et al. 2019 [167] & & & & & & $x$ & & & & & & & & & & & & & \\
\hline Oborski $2016[168]$ & & & & & & & & & & & & & & & $\mathrm{x}$ & & & & $x$ \\
\hline Ocker et a. 2019 [169] & & & & $\mathrm{x}$ & & & & & & & & & & & & & $x$ & & \\
\hline $\begin{array}{l}\text { Otto, Vogel-Heuser and Niggemann } \\
2018[108]\end{array}$ & & & & & & & & & & & & & & & & & & & $\mathrm{x}$ \\
\hline Panetto et al. 2019 [104] & & $\mathrm{x}$ & $\mathrm{x}$ & & & & & & $\mathrm{x}$ & $\mathrm{x}$ & & & & & & $\mathrm{x}$ & & & $x$ \\
\hline Penas et al. 2017 [12] & $x$ & $\mathrm{x}$ & & $\mathrm{x}$ & & & & & $\mathrm{x}$ & & & $x$ & & & $\mathrm{x}$ & $x$ & & & \\
\hline Pereira and Romero 2017 [80] & & & & $x$ & & & & & $x$ & & & & $x$ & & & $x$ & & & \\
\hline Peres et al. 2018 [170] & & & & & & & & & & $\mathrm{x}$ & & & & & & & & & \\
\hline Peruzzini and Pellicciari 2017 [171] & & & & & & & & & & $\mathrm{x}$ & & & & & & & & & $x$ \\
\hline $\begin{array}{l}\text { Pirvu, Zamfirescu and Gorecky } 2016 \\
\text { [74] }\end{array}$ & $\mathrm{x}$ & & & & & & & & $\mathrm{x}$ & & & & & & & & & & $\mathrm{x}$ \\
\hline Posada et al. 2015 [105] & & & & $\mathrm{x}$ & & & & & $\mathrm{x}$ & & & $\mathrm{x}$ & & & & & & & \\
\hline Qu et al. 2019 [172] & & & & & & & & & $\mathrm{x}$ & & & $\mathrm{x}$ & & & $x$ & & & & \\
\hline Rama et al. 2016 [110] & & & & $\mathrm{x}$ & & & & & & & & & & & & & & & \\
\hline Ribeiro and Bjorkman 2018 [73] & & & & & & & & $x$ & & & & & & & & & & $\mathrm{x}$ & $\mathrm{x}$ \\
\hline Ribeiro and Hochwallner 2018 [67] & & & & & & & & & & & & & & & & & & & $x$ \\
\hline Rojas et al. 2017 [39] & & & & $x$ & $\mathrm{x}$ & & & & $x$ & & & & & & & $\mathrm{x}$ & & & \\
\hline Rojas and Rauch 2019 [173] & & $\mathrm{x}$ & & & & & & & & & & & & & & & & & \\
\hline Ruppert et al. 2018 [40] & $\mathrm{x}$ & & $\mathrm{x}$ & & & & & $\mathrm{x}$ & & & $\mathrm{x}$ & & $\mathrm{x}$ & & & & & & $\mathrm{x}$ \\
\hline $\begin{array}{c}\text { Sanderson, Chaplin and Ratchev } 2018 \\
{[86]}\end{array}$ & & & & $\mathrm{x}$ & & & & $\mathrm{x}$ & $\mathrm{x}$ & $\mathrm{x}$ & & & $\mathrm{x}$ & & & & & & \\
\hline Sanislav and Miclea 2012 [174] & & & & & & $\mathrm{x}$ & & & & & & & & & & & & $\mathrm{x}$ & \\
\hline $\begin{array}{l}\text { Schuhmacher, Baumung and Hummel } \\
2017 \text { [175] }\end{array}$ & & & & & & & & & $\mathrm{x}$ & & & & & & & & & & \\
\hline Shafiq et al. 2015 [176] & & & & & & & & & & & & & & & & & & & $x$ \\
\hline Shafiq et al. 2016 [177] & & & & & & & & & & & & & & & & & & & $\mathrm{x}$ \\
\hline Shamim et al. 2017 [114] & & & & & & & & & & & $\mathrm{x}$ & & & & & & & & \\
\hline Song et al. 2017 [178] & & $\mathrm{x}$ & & & & $\mathrm{x}$ & $x$ & & & & & & & & & & & & \\
\hline Song and Moon 2019 [179] & & & & & & $\mathrm{x}$ & $\mathrm{x}$ & & & & & & $x$ & $x$ & & & & & \\
\hline Sun, Zhou and Yang 2018 [180] & & & & & & & $x$ & & & & & & & & & & & & \\
\hline Tang et al. 2017 [101] & & & & & & & & & $x$ & $\mathrm{x}$ & & $x$ & & & & & & & $x$ \\
\hline Tang et al. 2018 [181] & & & & & & & & & $x$ & $x$ & & $x$ & & & & & & & $x$ \\
\hline Tao and Qi 2019 [65] & & & $\mathrm{x}$ & $\mathrm{x}$ & & & $\mathrm{x}$ & & & & & & & & & & $\mathrm{x}$ & & \\
\hline Tao et al. 2019 [182] & & & & & $\mathrm{x}$ & & & & & & & & & & & & & & \\
\hline Tarallo et al. 2018 [183] & & & & & & & & & & & & & $\mathrm{x}$ & $\mathrm{x}$ & & & & & \\
\hline Tavcar and Horvath 2019 [184] & & & & & & & & & & $\mathrm{x}$ & & & & $x$ & & & & & $\mathrm{x}$ \\
\hline $\begin{array}{l}\text { Terziyan, Gryshko and Golovianko } \\
2018[185]\end{array}$ & & & $\mathrm{x}$ & & & & & $\mathrm{x}$ & & & & & $\mathrm{x}$ & $\mathrm{x}$ & & & & & \\
\hline Thoben, Wiesner and Wuest 2017 [15] & & & & & & & & & & & & & & & & & $x$ & & \\
\hline $\begin{array}{c}\text { Thramboulidis and Christoulakis } 2016 \\
\text { [186] }\end{array}$ & & & & & & & & & $\mathrm{x}$ & & & & & & $\mathrm{x}$ & & & $\mathrm{x}$ & $x$ \\
\hline Tran et al. 2019 [103] & & & & & $\mathrm{x}$ & & & & $\mathrm{x}$ & $\mathrm{x}$ & & $x$ & & & & $x$ & & & $\mathrm{x}$ \\
\hline Trappey et al. 2016 [78] & & & & & & & & & $x$ & & $x$ & & & & & & & & \\
\hline Tsai and Lu 2018 [112] & & & & $x$ & & & & & & $\mathrm{x}$ & & & & $x$ & & & & & \\
\hline Tu, Lim and Yang 2018 [48] & & & & $x$ & & & & & & & & $\mathrm{x}$ & & & & & & & $\mathrm{x}$ \\
\hline Tuptuk and Hailes 2018 [187] & & & $x$ & & & & & $\mathrm{x}$ & & & & & & & & & & & \\
\hline $\begin{array}{l}\text { Uhlmann, Hohwieler and Geisert } 2017 \\
{[188]}\end{array}$ & & & & & & $\mathrm{x}$ & & & & & $\mathrm{x}$ & $\mathrm{x}$ & & & & & & & \\
\hline Upasani et al. 2017 [47] & & & & $\mathrm{x}$ & & & & & $x$ & & & & & & & $x$ & & & \\
\hline Wan et al. 2011 [10] & $x$ & $\mathrm{x}$ & & & & $x$ & & & & & $x$ & & & & & & & $\mathrm{x}$ & \\
\hline Wan et al. 2013 [25] & $\mathrm{x}$ & & & & & $x$ & & & $\mathrm{x}$ & & $\mathrm{x}$ & & & & & & & $\mathrm{x}$ & \\
\hline Wang et al. 2015 [189] & & & $\mathrm{x}$ & & & $\mathrm{x}$ & & & & & & & & & $x$ & & & & \\
\hline Wang, Torngren and Onori 2015 [49] & $x$ & $x$ & & $x$ & & & & & $x$ & & $x$ & & & $x$ & & & $\mathrm{x}$ & & $x$ \\
\hline Wang and Haghighi 2016 [55] & & & & & & $\mathrm{X}$ & & & & & $x$ & $\mathrm{x}$ & & $x$ & $\mathrm{x}$ & & & & $x$ \\
\hline Wang et al. 2016 [190] & & & & $x$ & & & & & $x$ & & $x$ & & & & & & & & \\
\hline Wang 2017 [191] & & & & $\mathrm{x}$ & & & $x$ & & & & & & & $\mathrm{x}$ & & & & & \\
\hline Wang, Zhang and Zhong 2020 [192] & & & & & & & & & & & & $x$ & & & & & & & \\
\hline Weyer et al. 2016 [106] & & & & $x$ & & $x$ & & $\mathrm{x}$ & & & $\mathrm{x}$ & & $x$ & & & & & & \\
\hline Woo et al. 2018 [57] & & & & $x$ & & & & & & & & $\mathrm{x}$ & & & & & & & \\
\hline Wu, Kao and Tseng 2011 [54] & & & & & $\mathrm{x}$ & $x$ & & & & & & $\mathrm{x}$ & & & & & & & \\
\hline Wu and Moon 2019 [193] & & & & $\mathrm{x}$ & & & & & & & & $x$ & & & & & & & \\
\hline Xu 2017 [194] & $x$ & & & & & & & & & & & & & & & & & & \\
\hline Xu and Hua 2017 [195] & $x$ & & & & & & & & & & & & & & & & & $x$ & \\
\hline Xu and Duan 2019 [196] & & & & $x$ & & & & & & & & $\mathrm{x}$ & & & & & & & \\
\hline Xu et al. 2018 [197] & & & & $x$ & & & & & & & & $x$ & & & & & & & \\
\hline Yao et al. 2018 [198] & & & & & & & & & & & & & & & $x$ & & & & \\
\hline Yu, Xu and Lu 2015 [199] & & & & & & & & & & & & & $x$ & & & & & & \\
\hline Yu et al. 2017a [77] & & & $\mathrm{x}$ & & & & & $\mathrm{x}$ & $x$ & & & $\mathrm{x}$ & & & & $x$ & & $\mathrm{x}$ & $\mathrm{x}$ \\
\hline Yu et al. 2017b [45] & & & & $\mathrm{x}$ & & & & & $\mathrm{x}$ & $\mathrm{x}$ & & $\mathrm{x}$ & & & & $\mathrm{x}$ & & & $x$ \\
\hline Yuan, Anumba and Parfitt 2015 [27] & $x$ & $\mathrm{x}$ & & & & & & & $x$ & & $\mathrm{x}$ & & $x$ & $x$ & & $\mathrm{x}$ & & & $x$ \\
\hline Zhang et al. 2017 [200] & & & & & & & & & $x$ & & & & & & & & & $x$ & \\
\hline Zheng et al. 2018 [201] & & & & & & & & & $x$ & $\mathrm{x}$ & $x$ & & & $x$ & & & & & \\
\hline
\end{tabular}




\begin{tabular}{|c|c|c|c|c|c|c|c|c|c|c|c|c|c|c|c|c|c|c|c|}
\hline Zhou, Liu and Liang 2016 [2] & & $\mathrm{x}$ & & & & & & & & & & & & $\mathrm{x}$ & & & & & \\
\hline Zhou et al. 2018 [202] & & & & & $\mathrm{x}$ & & & & & & & & & & $\mathrm{X}$ & & & & \\
\hline Zhou et al. 2019 [93] & $\mathrm{x}$ & & & & & & & & & & & $\mathrm{x}$ & & & $x$ & & & & \\
\hline Total & 19 & 18 & 15 & 47 & 14 & 20 & 12 & 14 & 46 & 19 & 24 & 37 & 20 & 20 & 25 & 14 & 14 & 11 & 29 \\
\hline
\end{tabular}

Table A.2 Characteristics of CPSs according to literature (less cited characteristics)

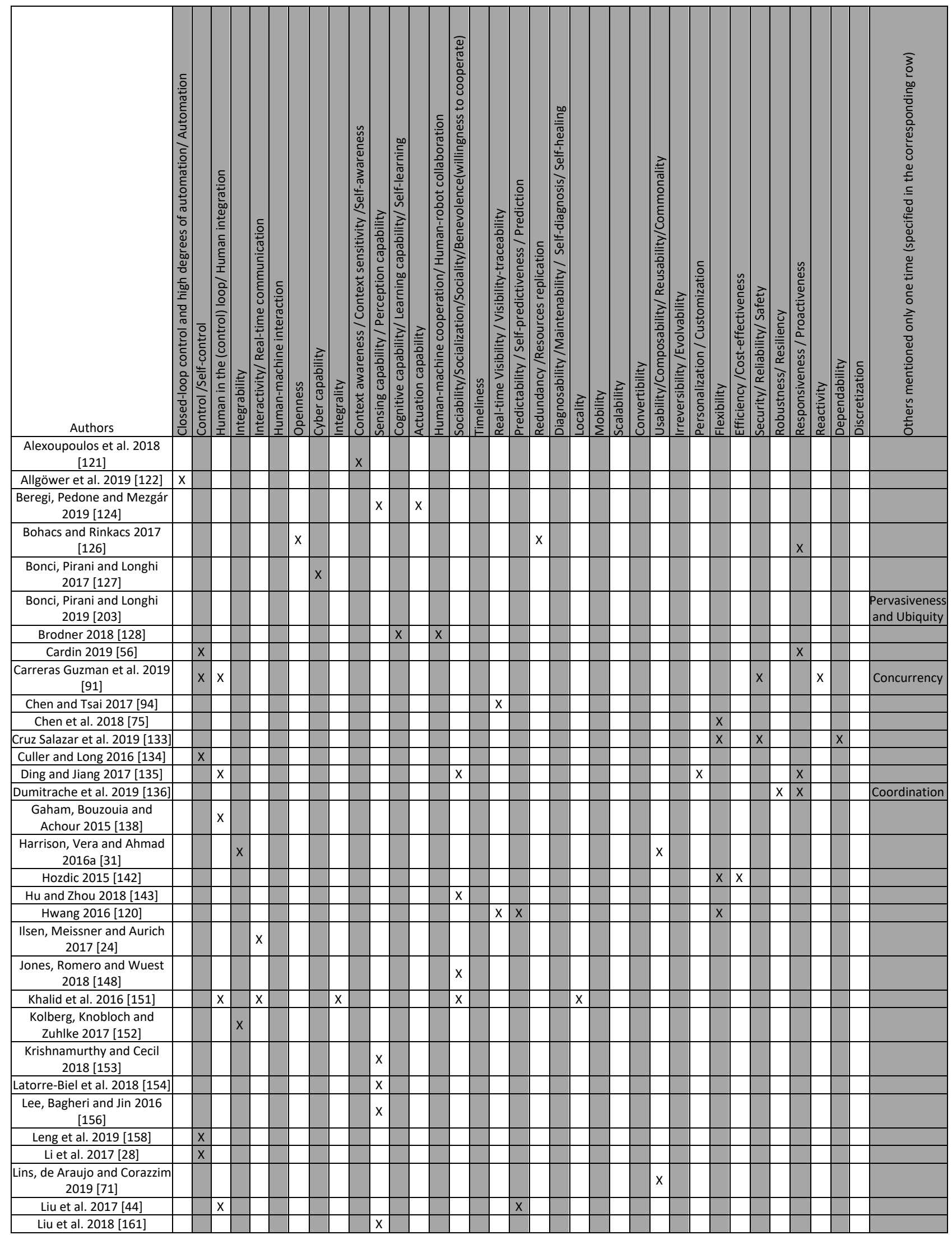




\begin{tabular}{|c|c|c|c|c|c|c|c|c|c|c|c|c|c|c|c|c|c|c|c|c|c|c|c|c|c|c|c|c|c|c|c|c|c|c|}
\hline Liu and Jiang 2019 [159] & & & & & & & & & & & & & & & & & & & & & & & & & & & & & & & $x$ & & & \\
\hline Liu et al. 2019 [162] & & & $x$ & & & & & & & & & & & & & $x$ & & & & & & & & & & & & & & & & & & \\
\hline Lu and Xu 2019 [58] & & & & & & & & & & $x$ & & & & & & & & & & & & & & & & & & & & & & & & \\
\hline Mittal et al. 2019 [204] & & & & $\mathrm{x}$ & & & & & & & & & & & & & & & & & & & & & & & & & & & & & & \\
\hline Monostori et al. 2016 [32] & & & & & & & & & & & & & & & & & & & & & & & & & & & & & & $\mathrm{x}$ & & & & \\
\hline \begin{tabular}{|l|} 
Mora et al. 2017 [34] \\
\end{tabular} & & & & & & & & & & & $\mathrm{x}$ & & $x$ & & & & & & & & & & & & & & & & & & & & & \\
\hline \begin{tabular}{|c|} 
Morel, Pereira and Nof 2019 \\
{$[165]$}
\end{tabular} & & & & & & & & & & & & & & $x$ & & & & & & & & & & & & & & & $x$ & $x$ & & & & \\
\hline Oborski $2016[168]$ & & & & & & & & & & & & & & & & & & & & & $\mathrm{x}$ & & & & & & & & $x$ & & & & & \\
\hline Penas et al. 2017 [12] & & & & & & & $\mathrm{x}$ & & & & & $\mathrm{x}$ & & & & & & & & & & & & & & & & & & & & & & \\
\hline Peres et al. 2018 [170] & & & & & & & & & & $\mathrm{X}$ & & & & & & $\mathrm{X}$ & & & & & $\mathrm{x}$ & & & & & & & & & & & & & \\
\hline \begin{tabular}{|c|} 
Peruzzini and Pellicciari 2017 \\
{$[171]$}
\end{tabular} & & & & & & & & & & & & & & & & & & & & & & & $x$ & & & & & & & & & & & \\
\hline \begin{tabular}{c|} 
Pirvu, Zamfirescu and \\
Gorecky $2016[74]$
\end{tabular} & & & & & & & & & $\mathrm{x}$ & & & & & $x$ & & & & & $\mathrm{x}$ & & & & & $x$ & & & & & & & & & & \\
\hline Posada et al. 2015 [105] & & & & & & & & & & & & & $\mathrm{X}$ & & & & & & & & & & & & & & & & & & & & & \\
\hline Qu et al. 2019 [172] & & & & & $x$ & & & & & & & & & & & & & & & & & & & & & & & & & & & & & \\
\hline Rama et al. 2016 [110] & & & & & $\mathrm{X}$ & & & & & & & & & & & & & & & & & & & & & & & & & & & & & \\
\hline \begin{tabular}{|c|} 
Ribeiro and Bjorkman 2018 \\
{$[73]$}
\end{tabular} & & & & $x$ & & & & & & & & & & & & & & $x$ & & & $x$ & $\mathrm{x}$ & & & $x$ & & & & & & & & & \\
\hline $\begin{array}{c}\text { Ribeiro and Hochwallner } \\
2018[67] \\
\end{array}$ & & & & $x$ & & & & & & & & & & & & $x$ & & $x$ & & & & $\mathrm{x}$ & $x$ & & & & & $x$ & & & & & & \\
\hline Rojas et al. 2017 [39] & & & & $\mathrm{x}$ & & & & & & & $\mathrm{x}$ & $x$ & $x$ & & & & & & & & & & & & & & & & & & & & & \\
\hline Rojas and Rauch 2019 [173] & & & & & $\mathrm{x}$ & & & & & $x$ & & & & & & & & & & & & & & & & & & & & & $\mathrm{x}$ & & & \\
\hline \begin{tabular}{|c|}
$\begin{array}{c}\text { Sanderson, Chaplin and } \\
\text { Ratchev } 2018 \text { [86] }\end{array}$ \\
\end{tabular} & & & & & & & & & & $x$ & & & & & & & & & & & & & & & & & & & & & & & & \\
\hline $\begin{array}{c}\text { Sanislav and Miclea } 2012 \\
{[174]}\end{array}$ & $x$ & & & & & & & $\mathrm{x}$ & & & & & & & & & & & & & & & & & & & & & & & & $x$ & & \\
\hline $\begin{array}{c}\text { Scholze, Barata and Stokic } \\
2017 \text { [76] }\end{array}$ & & & & & & & & & & $x$ & & & & & & & & & & & & & & & & & & & & & & & & \\
\hline Shafiq et al. 2015 [176] & & & & & & & & & & & & & & & & & & & & & & & & & & & $\mathrm{x}$ & & & & & & & \\
\hline Shafiq et al. 2016 [177] & & & & & & & & & & & & & & & & & & & & & & & & & & & $\mathrm{x}$ & & & & & & & \\
\hline Song and Moon 2019 [179] & & & & & & & & & & & & & & & & $x$ & & & & & & & & & & & & & & & & & & \\
\hline Stern and Becker 2019 [205] & & & & & & $x$ & & & & & & & & & & & & & & & & & & & & & & & & & & & & \\
\hline \begin{tabular}{|l|} 
Tang et al. 2017 [101] \\
\end{tabular} & & & & & & & & & & & & & & & & & & & & & & & & & & & & & & & & & $\mathrm{X}$ & \\
\hline Tang et al. 2018 [181] & & & & & & & & & & & & & & & & & & & & & & & & & & & & & & & & & $\mathrm{x}$ & \\
\hline Tao and Qi 2019 [65] & & & & & & & & & & & & & & $\mathrm{x}$ & & & & & & & & & & & & & & & & & & & & \\
\hline \begin{tabular}{|c|} 
Tavcar and Horvath 2019 \\
{$[184]$}
\end{tabular} & & & & & & & & & & & & $x$ & & & & & & & & & & & & & & & & & & & & & & \\
\hline $\begin{array}{l}\text { Thoben, Wiesner and Wuest } \\
2017[15]\end{array}$ & & & & & & & & & & & & & $x$ & & & & & & & & & & & & & & & & & & & & & \\
\hline \begin{tabular}{|c|} 
Thramboulidis and \\
Christoulakis 2016 [186] \\
\end{tabular} & & & & & & & $x$ & & & & & & & & & & & $x$ & & & $x$ & & & $x$ & & $\mathrm{x}$ & & & & & & & & \\
\hline Tran et al. 2019 [103] & & & & & & & & & & & $\mathrm{x}$ & $\mathrm{X}$ & & & & & & $\mathrm{X}$ & & & & & & & & & & & & & & & & \\
\hline Trappey et al. 2016 [78] & & & & & & & & & & & & & & & $x$ & & & & & & $x$ & & & & & & & $x$ & & & & & & $\begin{array}{c}\text { Fault } \\
\text { tolerance }\end{array}$ \\
\hline Tsai and Lu 2018 [112] & & & & & & & & & & $x$ & & & & & & & & & & & & & & & & & & & & & & & & \\
\hline Tu, Lim and Yang 2018 [48] & & & & & & & & & & & & & & & & & & & & & & & & & & & & & & $x$ & & & & \\
\hline $\begin{array}{c}\text { Tuptuk and Hailes } 2018 \\
{[187]} \\
\end{array}$ & & & & & & & & & & $\mathrm{x}$ & & & & & & & & & & & & & $x$ & & & & & $x$ & & & & & & \\
\hline $\begin{array}{c}\text { Uhlmann, Hohwieler and } \\
\text { Geisert } 2017 \text { [188] }\end{array}$ & & & & & & & & & & & & $x$ & & & & & & & & & & & & & & & & & & & & & & \\
\hline Wan et al. 2011 [10] & $\mathrm{X}$ & & & & & & & $\mathrm{X}$ & & & & & & & & & & & & & & & & & & & & & & & & & & \\
\hline Wan et al. 2013 [25] & $\mathrm{x}$ & & & & & & & $\mathrm{x}$ & & & & & & & & & & & & & & & & & & & & & & & & & & \\
\hline Wang et al. 2015 [189] & & & & & & & & & & & $\mathrm{x}$ & & & & & & & & & & & & & & & & & & & & & & & \\
\hline $\begin{array}{l}\text { Wang, Torngren and Onori } \\
2015 \text { [49] }\end{array}$ & & & $x$ & & & & $\mathrm{x}$ & & & & & $x$ & & & & & & & & & & & & & & & & & & & & & & \\
\hline $\begin{array}{l}\text { Wang and Haghighi } 2016 \\
{[55]}\end{array}$ & & & & & & & & & & & & & & & & $x$ & & & & & & & & & & & & & $x$ & & & & & \\
\hline Wang et al. 2016 [190] & & & & & & & & & & & & & & & & & & & & & & & & & & & & & & & & & & Negotiation \\
\hline $\begin{array}{l}\text { Wang, Zhang and Zhong } \\
2020[192]\end{array}$ & & & & & & & & & & & & & & & & $x$ & & & & & & & & & & & & & & $x$ & & & & \\
\hline Weyer et al. 2016 [106] & & & & & & & & & & & & & & & & & & & & & $\mathrm{X}$ & & & & & & & & & & & & & \\
\hline $\begin{array}{l}\text { Wu, Kao and Tseng } 2011 \\
{[54]}\end{array}$ & & & & & & & & & & & & & & & & & & & & $x$ & & & & & & & & & & & & & & \\
\hline Xu and Duan 2019 [196] & & & & & $\mathrm{x}$ & & & & & & & & & & & & & & & & & & & & & & & & $x$ & & & & & \\
\hline Yao et al. 2018 [198] & & & & & & $x$ & & & & & & & & & & & & & & & & & & & & & & & & & & & & \\
\hline Yu et al. 2017a [77] & & & & & $x$ & & & & & & & & & & & & & $\mathrm{X}$ & & & & & $\mathrm{X}$ & & & & & $\mathrm{X}$ & & & & & & \\
\hline Yu et al. 2017b [45] & & & & & & & & & & & & $\mathrm{x}$ & & & & & & & & & & & & & & & & & & $x$ & & & & \\
\hline $\begin{array}{l}\text { Yuan, Anumba and Parfitt } \\
2015[27]\end{array}$ & $x$ & & & & & & & & & & & & $x$ & & $x$ & & & & & & & & & & & & & & & & & & & Uncertainty \\
\hline Zhang et al. 2017 [200] & & & & & & & & & & & & & & & & & & & & & $\mathrm{X}$ & & & & & & & & & & & & & \\
\hline Zheng et al. 2018 [201] & & & & & & & & & & $x$ & & & & & & $x$ & & & & & & & & & & & & & & & & & & \\
\hline Zhou, Liu and Liang 2016 [2] & & & & & & & & & & & & & & & & & & & & & & & & & & $\mathrm{x}$ & & & & & & & & \\
\hline Zhou et al. 2019 [93] & & & $\mathrm{x}$ & & & & & & & & & $x$ & & & & & & & & & & & & & & & & & & & & & & \\
\hline Total & 5 & 5 & 8 & 6 & 7 & 3 & 4 & 4 & 2 & \begin{tabular}{|l|l}
9 & \\
\end{tabular} & 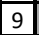 & 9 & \begin{tabular}{l|l}
3 & 4 \\
\end{tabular} & 6 & 2 & \begin{tabular}{|l|l|}
2 & 9 \\
\end{tabular} & 1 & 5 & 2 & 1 & 7 & 2 & 6 & 2 & 2 & 6 & 3 & 6 & 4 & 9 & 4 & 2 & 2 & - \\
\hline
\end{tabular}




\section{List of abbreviations}

C1. Complexity/heterogeneity encapsulation

C2. Interoperability, Connectivity, Communication, Networking capability

C3. Service orientation

C4. Modularity, Autonomy, Self-capabilities, Decentralization

C5. Virtualization, Real-time capability

C6. Computational capability

C7. Cooperation, Collaboration

C8. Scalability, Dynamic reconfigurability, Adaptability

C9. Predictability, Diagnosability 